This is an electronic reprint of the original article. This reprint may differ from the original in pagination and typographic detail.

Author(s): Eerola, Tuomas; Vuoskoski, Jonna

Title: $\quad$ A review of music and emotion studies: Approaches, emotion models, and stimuli

Year: $\quad 2013$

Version:

Please cite the original version:

Eerola, T., \& Vuoskoski, J. (2013). A review of music and emotion studies:

Approaches, emotion models, and stimuli. Music perception, 30(3), 307-340.

https://doi.org/10.1525/MP.2012.30.3.307

All material supplied via JYX is protected by copyright and other intellectual property rights, and duplication or sale of all or part of any of the repository collections is not permitted, except that material may be duplicated by you for your research use or educational purposes in electronic or print form. You must obtain permission for any other use. Electronic or print copies may not be offered, whether for sale or otherwise to anyone who is not an authorised user. 
A Review of Music and Emotion Studies: Approaches, Emotion Models, and Stimuli Author(s): Tuomas EerolaJonna K. Vuoskoski

Source: Music Perception: An Interdisciplinary Journal, Vol. 30, No. 3 (February 2013), pp. 307-340

Published by: University of California Press

Stable URL: http://www.jstor.org/stable/10.1525/mp.2012.30.3.307

Accessed: 29/09/2014 03:51

Your use of the JSTOR archive indicates your acceptance of the Terms \& Conditions of Use, available at http://www.jstor.org/page/info/about/policies/terms.jsp

JSTOR is a not-for-profit service that helps scholars, researchers, and students discover, use, and build upon a wide range of content in a trusted digital archive. We use information technology and tools to increase productivity and facilitate new forms of scholarship. For more information about JSTOR, please contact support@jstor.org. 


\section{A Review of Music and Emotion Studies: Approaches, Emotion Models, and Stimuli}

Tuomas Eerola \& Jonna K. Vuoskoski University of Jyvàskylä, Jyváskylä, Finland

THE FIELD OF MUSIC AND EMOTION RESEARCH HAS grown rapidly and diversified during the last decade. This has led to a certain degree of confusion and inconsistency between competing notions of emotions, data, and results. The present review of 251 studies describes the focus of prevalent research approaches, methods, and models of emotion, and documents the types of musical stimuli used over the past twenty years. Although self-report approaches to emotions are the most common way of dealing with music and emotions, using multiple approaches is becoming increasingly popular. A large majority ( $70 \%$ ) of the studies employed variants of the discrete or the dimensional emotion models. A large proportion of stimuli rely on a relatively modest amount of familiar classical examples. The evident shortcomings of these prevalent patterns in music and emotion studies are highlighted, and concrete plans of action for future studies are suggested.

Received: October 28, 2011, accepted April 17, 2012.

Key words: emotion, review, music, stimuli, theoretical

I T HAS OFTEN BEEN SUGgeSTED THAT THE emotional effects of music are the most important reason why people engage in musical activities (Juslin \& Laukka, 2004; Sloboda \& O'Neill, 2001). The emotional power of music is the reason for its application in areas as diverse as the gaming industry, film industry, marketing, and music therapy, yet the scientific insights into this phenomenon are far from complete or revealing. Contemporary research on music and emotion is a popular topic within the fields of music cognition, music psychology, and neuroscience of music, and is-by definition-interdisciplinary. To date, a large number of research approaches have been used to explore why and how music has such a strong grip on listeners-regardless of differences in education, personality, musical taste, or culture. The contents of music that induces emotion have been extracted and manipulated in numerous ways in order to understand the cues that lead us to assign emotional labels to music. And over the years, a large variety of music-from artificial melodies to live opera performances-has been used for this purpose. Because of the range of approaches, models and settings used in music and emotion studies, one of the most current and potent criticisms is that all this research has not really resulted in a set of coherent findings since large discrepancies exist concerning exactly what is being studied (e.g., Juslin \& Västfjäll, 2008). This is not entirely surprising given that emotion research in general has acknowledged the challenges in defining emotions in a way that would be acceptable to most researchers (Frijda, 2007; Izard, 2007). Emotions in music may even be a more complicated topic since we enter the realm of aesthetics and so-called "positive emotions," that are in contrast to the survival-oriented emotions (such as fear and anger) that have received far greater attention within mainstream psychology.

The most fundamental question addressed in music and emotion studies is arguably, "How does music evoke emotions in listeners?" This question can be broken down into separate areas of inquiry, such as: 1) What are the putative emotions induced by music, and which components contribute to these? 2) How are emotions conveyed by music (e.g., elements of music, lyrics, sound quality, etc.)? 3) What are the contributions of the situation (e.g., alone/in company, different activities), listener attributes (e.g., expertise, personality), and the intention to regulate one's own affective state? 4) Are the processes involved largely learned or universal, and how are they related to other perceptual, cognitive, and meaning-generation processes in our minds? Most such pivotal issues branching out from the fundamental question require multiple approaches (e.g., cross-cultural, biological, developmental) in order to be investigated fruitfully and convincingly. The whole definition of the phenomenon itself is intertwined with the theoretical and operational notions of different emotion models, which give rise to entirely different assumptions of the processes involved (e.g.,

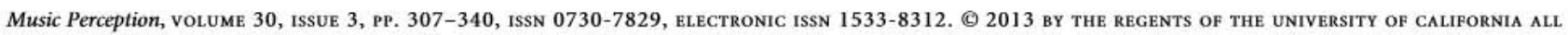
RIGHTS RESERVED. PLEASE DIRECT ALL REQUESTS FOR PERMISSION TO PHOTOCOPY OR REPRODUCE ARTICLE CONTENT THROUGH THE UNIVERSITY OF CALIFORNIA PRESS'S RIGHTS AND PERMISSIONS WEBSITE, HTTP://WWW.UCPRESSJOURNALS.COM/REPRINTINFO.ASP. DOI: 10.1525/MP.2012.30.3.307 
automatic and universal basic emotions versus highly specific, aesthetic feelings of awe). Finally, the concept of music itself is-naturally-also a central building block of the fundamental question, and it is worth asking what kinds of music have been used in the studies exploring these core topics. By dissecting the fundamental question into these broad elements, we aim to review the recent studies on music and emotion, and to provide a summary of the approaches, emotion models, and musical stimuli used in these studies. Summarizing the past research efforts in a novel way may allow us to highlight critical issues that have been previously overlooked. Do we take it for granted that basic emotions are the most commonly studied emotions in the field of music and emotions? How common is it to combine self-reports with physiological measures and individual variables such as personality traits? How is the issue of emotion recognition vs. emotion induction distributed across all the research approaches and emotion models used? Do the stimuli used in emotion studies reflect the everyday experiences and tastes of music listeners? These are all examples of questions that are important for the growing numbers of researchers coming into the field, and may allow those already familiar with the field to investigate more precisely and systematically the ways in which music interacts with the emotional lives of everyday listeners.

After the publication of Juslin and Sloboda's (2001) influential handbook on music and emotions, a number of overviews have documented the state of the field. These studies have been made from a wide range of perspectives. Västfjäll (2002) qualitatively reviewed mood induction procedures in a host of studies (including marketing studies) and suggested recommendations for future studies. An influential meta-analysis by Juslin and Laukka (2003) analyzed the communication accuracy of emotions via music and speech using strict meta-analysis criteria. For the present work this is the most directly relevant previous study, although their meta-analysis was restricted to studies that employed discrete emotions. One of the central findings of this meta-analysis was to show the overall decoding accuracy of emotions. Our aim is to update the findings to see whether researchers in the field have indeed still "almost exclusively studied discrete emotions" (p. 776, Juslin \& Laukka, 2003). Instead of focusing on communication accuracy, we aim to provide an updated overview of the approaches, models, and stimuli employed within the field. Juslin and Laukka also provided a partial summary of the stimuli used in the reviewed studies (genres, instruments, paradigms for generating the stimuli) and concluded that a "wide range of musical styles" is used in music and emotion studies, classical music being the most common. Although we intend to characterize the stimulus materials in a more exhaustive fashion, this previous work will also provide an interesting point of comparison. The third comprehensive survey of music and emotion studies is the work by Gabrielsson and Lindström (2001), which focused on performance and structural features that are assumed to contribute to emotional expression in music. Their summary covered 32 empirical studies-starting chronologically from Hevner (1936) through to Balkwill and Thompson (1999) - that examine the role of separate musical factors (tempo, articulation, harmony, timbre, etc.) in the expression of different emotions. As well as these major summaries, a number of journal articles by eminent scholars have made succinct digests of previous research in the field, and various suggestions for further research (e.g., Juslin \& Sloboda, 2010; Juslin \& Västfjäll, 2008; Koelsch, Fritz, Cramon, Müller, \& Friederici, 2006; Peretz, 2010).

To conclude, the accumulated mass of music and emotion studies has reached a critical point, in so far that it has become increasingly diverse in terms of research approaches, methods, and models, to the point of losing consistency. There is the ever-growing sense that "studies thus far have produced data that are collectively confusing and internally inconsistent" (Juslin \& Västfjäll, 2008, p. 574). This confusion is mainly caused by variations in models, terminologies, and underlying mechanisms. In the following pages, we will first attempt to describe the dominant trends in music and emotion studies, and then address the evident shortcomings of these studies in detail.

\section{Review Method}

\section{INCLUSION CRITERIA}

To form an overview of the approaches, emotion models, and stimuli employed within the field of music and emotions, we reviewed studies published since 1988 until February 2009 in refereed journals or conference proceedings, thus spanning 20 years of studies. Despite the scattered nature of music and emotion publication channels (psychology, engineering, musicology, acoustics, and even medicine), we attempted to collect the essential studies from PsycINFO and RILM using suitable keywords (music, emotion, affect* mood, express $^{*}$ ). We also used various other sources to supplement these studies. To constrain the number of studies we left out individual book chapters, non-English texts, and unpublished dissertations. A total of 251 studies were annotated in terms of the (1) research 
approach, (2) emotion model, (3) locus of emotion, and (4) stimulus details. Focusing in this way ensured that the work already done by Juslin and Laukka (2003) was minimally replicated and so our work would provide a different, updated, and broader perspective to what the popular choices made by researchers within the field are.

\section{RESEARCH APPROACHES}

During the review process, research approaches were divided into seven broad categories: theoretical, selfreport, biological, clinical, developmental, music-analytic, and individual and cultural differences. These categories are not mutually exclusive as a study might employ both biological and self-report approaches (to give an example of a common overlap). Examples of studies that represent each category will be given later.

The theoretical approach consists of non-empirical formulations of emotions within the domain of music, including review studies. In other words, approaches without empirical evidence to support them. It should be noted that of course all empirical studies also use theoretical assumptions in order to falsify or corroborate these concepts; however, for the purposes of this review they have been classified under the type of empirical approach adopted. This definition also means that certain important theoretical contributions with a major empirical part are subsumed under different approaches. However, these few exceptions, namely, the application of the brunswikian lens model to music and emotion by Juslin (2000), proposal of the GERM model by Juslin, Friberg, and Bresin (2001), and the GEMS model by Zentner, Grandjean, and Scherer (2008) will be covered and discussed in the summary sections. Also, theoretical accounts may be more often documented in monographs than in articles (e.g., Juslin \& Sloboda, 2001; Kivy, 1990; Nussbaum, 2007), which render them invisible for this review. The self-report category therefore contains all studies that utilize a paradigm where a non-clinical sample of listeners or participants evaluates emotions either in music (expressed by music) or induced by music using any type of self-report method such as recognition tasks, Likert ratings, adjective lists, free verbal reports, diaries, and also non-verbal response formats such as assessing the similarity of two examples. The biological approach is appropriate for studies that employ any peripheral measure (e.g., skin conductance, heart rate, muscle tension, respiration, electrocardiogram, blood pressure, etc.) or a measure of the central nervous system (e.g., EEG, MEG, fMRI, PET). In neurological studies that involve pathologies, it should be noted that the research approach is not only neural, but also clinical.
The clinical approach means that these studies are based on clinical populations (e.g., brain pathology or a clinical group such as depressed patients). In spite of these studies typically using a control group consisting of a non-clinical population, they remain classified under the clinical approach, as their reactions are being noted only for their value as a control group. The term developmental approach is applied when the participants of the study are children (typically 3-8 years of age) and the main aim of the study is to examine developmental issues related to music and emotions. The music analytic approach refers to studies in which the actual musical features related to emotions are given an emphasis by means of music analysis (acoustic, musicological, or based on ratings of musical features by listeners), or direct manipulation of the particular musical features related to emotions. We do not consider a study manipulating arousal by means of selecting different kinds of music for low and high arousal conditions as music analytic unless the differences in collected emotion data are explained in terms of musical differences between the stimuli. The final category of approach-individual and cultural differencesincludes studies relating to personality and expertise as well as cross-cultural comparisons of emotional processing. Although the attention of cross-cultural comparisons is on intercultural differences rather than interindividual differences, both share a similar interest towards the generalizability of the findings of music and emotion research across populations, and explore how learning contributes to the recognition and induction of emotions in the context of music (cf. Elfenbein \& Ambady, 2002). Application areas for music and emotion research, such as consumer psychology and purely medically oriented studies, were deemed to be outside of the scope of this review. Similarly, studies relying mainly on a computational approach to emotions were excluded in order to constrain the focus of the review.

\section{EMOTION MODELS}

The theoretical models of emotion taken up by the studies were divided into four classes: discrete, dimensional, miscellaneous, and music-specific. This division is modified from the major theoretical traditions of emotion measurement (Barrett \& Wager, 2006; Mauss \& Robison, 2009; Scherer, 2004) although it may not accurately distinguish the source (basic emotion, core affect, music) and the structure (discrete or dimensional) of emotions within the particular models, as discussed later. The discrete model of emotion relates to the theory of basic emotions, which asserts that all emotions 
can be derived from a finite set of innate basic emotions. These typically include fear, anger, disgust, sadness, and happiness (Ekman, 1992; Panksepp, 1998), but may also include emotions such as shame, embarrassment, contempt, and guilt (see Ortony \& Turner, 1990). In this review, studies within the discrete framework for emotions include all variants of the basic emotions, even if only a limited number of emotion categories have been used (e.g., happy and sad). These are the type of studies Juslin and Laukka reviewed in 2003 and their summary included the type of emotion terms used and the number of emotions typically included in the studies. For this reason, we will not replicate these details here.

The dimensional model for emotions is the other commonly used emotion model in psychology, and the most famous example of this is the circumplex model (Russell, 1980). This model represents emotions as a mixture of two core dimensions, valence and arousal, which are two continua that are orthogonally situated in the affective space. This model has received support in large-scale studies of self-reported emotions (e.g., Barrett \& Russell, 1999), a cross-cultural comparison (Russell, 1983), and psychometric studies (reviewed in Posner, Russell, \& Peterson, 2005). In this review, the dimensional model for emotions includes all studies that employ valence (or pleasant - unpleasant), arousal/activity, or other theoretically dimensional concepts (e.g., potency, tension arousal, etc.).

Miscellaneous models for emotion in music include a motley collection of emotion concepts such as intensity, preference, similarity, tension, or some other construct closely linked to emotions in general. Although the term tension was featured in two of our categories of emotion model, deciding the appropriate one was fairly straightforward as tension has been used in the musicspecific sense in several studies (Krumhansl, 1998; McAdams et al., 2004) and as a dimensional construct by only a few (e.g., Ilie \& Thompson, 2006). Rather than including a myriad of studies featuring preference or liking in the context of music, we only included such studies of preference to this review that contained an explicit emotion task.

Both discrete and dimensional emotion models concentrate on a small set of evolutionary emotions that have important functions when adapting the individual to events that have material consequences for the individual's well-being. In contrast, music rarely has any such effects on the individual's physical or psychological integrity. This issue has been taken up by work that has initially compiled emotion lists and extracted the underlying factors that are directly relevant for music (Zentner et al., 2008). In this review, the term music-specific refers to studies that employ just such a model of emotions. As in the case of research approaches, there is often overlap, and any study may utilize multiple models for emotions. Thus, where necessary, a study will be coded as featuring several emotion models. In addition, there is an overlap between the classes of emotion models, since the components of a musicspecific model may be either discrete or dimensional, and basic emotion terms may be operationally defined to form dimensions (e.g., happy-sad continuum). The purpose of the model division is to emphasize the epistemological sources of the emotion models.

\section{LOCUS OF EMOTION}

The locus of emotion-coined by Evans and Schubert in 2008-indicates whether the study addresses felt emotions (also known as induced emotions, or internal locus) or perceived emotions (external locus). This difference between the emotion actually experienced by the listener (hereafter, felt) and the emotion recognized in the music, (or expressed by music; hereafter, perceived) is of fundamental importance (Gabrielsson, 2001). A difference in the locus of emotion may sometimes lead to widely differing results (Konečni, Brown, \& Wanic, 2008; Zentner et al., 2008), even if the occasional, direct comparisons between felt and perceived emotion have not revealed significant differences between the two (see Evans \& Schubert, 2008; Vieillard et al., 2008). It is probable that largely different underlying processes are involved in the two kinds of emotional locus. Moreover, accurately capturing felt emotions is known among the research community to be a challenging task (see e.g., Roy, Mailhot, Gosselin, Paquette \& Peretz, 2008). The locus of emotion was classified as internal if the instructions stated that the participants should focus on their own emotional experiences or on the emotions that the music induces or arouses in them. This was in contrast to directions that emphasized the perception and recognition of emotions represented or expressed by music (external locus).

MUSIC STIMULI

The music used as stimulus material in the studies was annotated in terms of total number of pieces, duration, as well as the musical genres they represented. We also coded the nature of the stimuli and how the initial selection of the stimuli was carried out. Regarding the number of stimuli, it was the number of separate experimental stimuli rather than the number of individual compositions/songs that was counted, as often only 
a few compositions (two or three) were manipulated in terms of tempo or register to create dozens of variants for the experiment (e.g., Husain, Thompson, \& Schellenberg, 2002; Ilie \& Thompson, 2006). Therefore, our estimation of the stimulus quantity is a generous estimate, because the variants of the same musical source are calculated as separate stimuli.

The musical genres featured in the studies were categorized into classical, mixed, pop/rock, ethnic, film music, and custom-made. The classical genre contained any period of classical music (baroque, classicism, romantic, and modern). The mixed category was used when the experiment featured several distinct genres (e.g., classical, jazz, pop). Ethnic music was appropriate for cross-cultural studies that have employed nonWestern musical excerpts. We also tabulated whether the stimuli were natural (i.e., real recordings) or artificial excerpts (i.e., synthetically generated or isolated aspects of music such as sound samples or MIDI renditions), and what musical aspects were actually manipulated. We also catalogued whether the stimuli were chosen by the researchers, by a previous study, by a panel of experts, or by the participants themselves. Due to the high demands of controlling for possible confounds, most music and emotion studies probably rely on experimenter-chosen stimuli. However, the method for selecting the stimulus material is probably of great importance, especially for studies focussing on felt emotions. It is known that participant-selected music is more effective when music is used as a diversion in painful operations (Pelletier, 2004; also MacDonald et al., 2003), and more likely to give rise to chill experiences (Blood, Zatorre, Bermudez, \& Evans, 1999; Grewe, Nagel, Kopiez, \& Altenmüller, 2007a) than music chosen by researchers.

Finally, we made an effort to assess whether the participants were likely to have been exposed to the excerpts beforehand. Certain canonical classical music pieces (e.g., Albinoni's Adagio) are typical examples of excerpts that the participants might already be familiar with. The coding of all the variables was done by the authors in the following manner: after the initial review phase, the final coding categories and terminologies were decided. Then each author coded over half of the whole corpus, and the discrepant items in the overlapping studies were discussed. After this, the coding was slightly revised and both authors double checked the part that had been coded by the other. The only truly subjective measure was the issue of familiarity with the stimuli, in which case we had to rely on our own intuitions rather than on objective accounts of exposure.

\section{Results}

\section{EMOTION MODELS: AN OVERVIEW OF THE RESULTS}

Discrete emotion models. The principal findings of the studies regarding discrete emotions show that emotions such as happiness, anger, sadness, and tenderness are accurately perceived in music, even by such special populations as children (e.g., Adachi \& Trehub, 1998; Dalla Bella, Peretz, Rousseau, \& Gosselin, 2001; Nawrot, 2003), members of different cultures (Balkwill \& Thompson, 1999; Fritz et al., 2009), and braindamaged patients (Gosselin et al., 2005; Peretz, Gosselin, \& Bouchard, 1998). Most of these discrete emotions may also be induced in listeners by using particular music, which also result in discriminable patterns of physiological (Baumgartner, Esslen, \& Jancke, 2006; Etzel, Johnsen, Dickerson, Tranel, \& Adolphs, 2006) and neural responses (Schmidt \& Trainor, 2001). These emotions are the most frequently featured $(>30 \%)$ in music and emotion studies, and the majority of these studies utilized a self-report approach, the dominant approach in this field. The popularity of discrete emotions is without doubt related to the fact that categories lend themselves easily to recognition paradigmscommon in the above mentioned developmental, cross-cultural, and biological studies-but are also frequently used in production-recognition studies (e.g., Gabrielsson \& Juslin, 1996; Juslin, 1997a; Laukka \& Gabrielsson, 2000). Interestingly, investigations focussed on exploring the relationships between emotions and individual factors (Kreutz, Ott, Teichmann, Osawa, \& Vaitl, 2008; Resnicow, Salovey, \& Repp, 2004), clinical states (Banich, Stolar, Heller, \& Goldman, 1992), or visual cues in emotion recognition (Baumgartner et al., 2006), adopt discrete emotions more frequently than other emotion models. This is probably another aspect of how concepts that are known to be easily discriminated and explained make their way easily into subsequent studies of emotions despite the epistemological assumptions and limitations related to them.

The main difference between discrete emotion research in general and in music and emotion studies is that in the context of music the emotion categories have typically been modified by replacing musically inappropriate categories such as disgust and surprise with more fitting categories such as tenderness or peacefulness (e.g., Balkwill \& Thompson, 1999; Gabrielsson \& Juslin, 1996; Vieillard et al., 2008). This is perhaps indicative of the emotional functions of music that may generally be more positive (Juslin \& Laukka, 2004; Zentner et al., 2008) than the emotions experienced in everyday life situations (i.e., basic emotions that emphasize the 
survival aspects of affects). Accordingly, the choice of emotion categories may be too limited, and the impressive set of results could be interpreted as mainly showing a broad affective distinction between positive and negative emotions, thus being of limited value to a deeper understanding of emotions in music. Another significant limitation is the focus on a mixed and narrow palette of discrete emotions, which is not usually theoretically driven. For instance, over $75 \%$ of the studies adopting the discrete emotion model utilize happiness, sadness, and anger. The remainder of the emotion categories across studies often consist of different emotion concepts such as peacefulness, fear, joyfulness, solemnity, tenderness, distress, disgust, and surprise. This seriously limits the comparability of the results across studies.

Another sobering observation is that the results concerning several emotion categories could also be characterized by other emotion models to equal or better degree. For example, the discrimination of happy and sad emotions could also be delineated by differences in valence and arousal. Also, reliance on forced-choice paradigms and the presentation of a low number of emotion categories may both lead to overestimating the recognition success of these emotions. Finally, discrete emotion studies have excessively concentrated on perceived emotions, and the relationships between these and induced emotional experiences are often unclear (Gabrielsson, 2002; Scherer \& Zentner, 2001). Keeping in mind these caveats and the ongoing debate about the uniqueness of the physiological mechanisms concerning discrete emotions (e.g., Barrett \& Wager, 2006), as well as the disagreement about the exact number and labelling of emotion categories, we should regard the results on discrete emotions as the first exploratory phase of emotion and music studies.

Dimensional emotion models. During the last two decades, about a third of music and emotion studies have utilized dimensional emotion models. Valence and arousal are by far (> 70\%) the two most typical dimensions that participants are asked to rate independently on bipolar scales. The recognition of musical excerpts that are either high or low on valence or arousal-as well as the four combinations of these bipolar extremes-seems to be effortless for listeners (Ilie \& Thompson, 2006; Leman, Vermeulen, De Voogdt, Moelants, \& Lesaffre, 2005). Affects representing the same four quadrants may also be induced by musical excerpts (Rickard, 2004; Vieillard et al., 2008), and show unique patterns of neural (Altenmüller, Schuermann, Lim, \& Parlitz, 2002; Kabuto, Kageyama, \& Nitta, 1993) and physiological responses (Gomez \& Danuser, 2004; Witvliet \& Vrana, 2007)-although these seem to be more easily attributed to the arousal dimension than to the valence dimension. In our view, this probably relates to the special nature of musical experiences where negative emotions are less common (cf. Juslin \& Laukka, 2004). Affects typically classified as negative (e.g., melancholy) may be experienced as positive in the context of music-due to the fact that music does not have any material, negative effects on the listeners' well-being.

In comparison to general studies of emotions, variant formulations of the dimensional emotion model have received little attention in music-related research, despite the common observations that valence and arousal are not able to account for all the variance in music-mediated emotions (Bigand, Vieillard, Madurell, Marozeau, \& Dacquet, 2005; Collier, 2007; Ilie \& Thompson, 2006; Leman et al., 2005; Nykliček, Thayer, \& Van Doornen, 1997). This lack of resolution is also manifested in the way the two-dimensional model places emotions commonly regarded as remote in close proximity in the affective space; e.g., boredom and melancholy both are negatively valenced and low on arousal despite their notable differences in character (Scherer, 2004). These observations have led emotion researchers to seek other formulations of the dimensions (e.g., Schimmack \& Grob, 2000; Thayer, 1989), but surprisingly few of these developments have found their way into music and emotion studies; only a handful of studies have utilized other dimensions such as intensity, dominance, or tension in addition to the valence and arousal dimensions (e.g., Ilie \& Thompson, 2006; Leman et al., 2005; Luck et al., 2008; Schubert, 2007). The most critical flaw in past work concerning the use of dimensional emotion models in music, however, is the seemingly tenacious confidence in Russell's circumplex model (valence and arousal), despite the development of more empirically and neurologically convincing dimensional models in the late 1980s. For example, the Positive and Negative Affect Scale (PANAS by Watson, Clark, \& Tellegen, 1988) treats positive and negative valence as separate dimensions, and Thayer (1989) divides the affect space into dimensions of energy arousal and tension arousal. It is difficult to avoid the impression that a few popular studies (Nykliček et al., 1997; Schubert, 1999; Terwogt \& Van Grinsven, 1991) established the research agenda for the following decade, or that the field has suffered from a lack of theoretical reflection in the choice of emotions in general.

Miscellaneous emotion models. The prevalence of miscellaneous emotion models $(66 / 251)$ can be regarded as a reaction of the research community to 
many of the criticisms leveled at the discrete and dimensional models, outlined above. The concepts belonging to this category (intensity, preference, similarity, emotional expressiveness, and tension) seek to characterize aspects that are ignored by the discrete and dimensional models, although some of these concepts are present (but may have a different definition) in the other formulations of the dimensional model (e.g., tension).

There is no single emerging trend in the results concerning miscellaneous emotion models. The most frequent concept, preference/liking ( 14 out of 66 studies) is of borderline interest to emotions, although theoretically they are often considered as the simplest form of affect manifestations (Zajonc, 1980; for a discussion regarding preference in the context of music, see Scherer \& Zentner, 2001). In some studies liking/preference has been used as a substitute for valence (e.g., Brown, Martinez, \& Parsons, 2004). This idea was empirically tested by North and Hargreaves (1997). Although valence and preference have been observed to correlate highly, most studies acknowledge the difference between the two (Eerola \& Vuoskoski, 2011; Rawlings \& Leow, 2008; Ritossa \& Rickard, 2004). Similarly, studies claiming to investigate emotional intensity may actually be measuring something that constitutes the arousal dimension of the circumplex model (e.g., Schmidt \& Trainor, 2001). Studies devoted particularly to emotional intensity (Brittin \& Duke, 1997; Krumhansl, 1998; Lehmann, 1997) or expressivity (Kamenetsky, Hill, \& Trehub, 1997; Sloboda \& Lehmann, 2001) avoid the semantic labelling problem that concerns discrete and-to a certain degree-dimensional models. The results of these studies have suggested that intensity/expressivity differences can be both induced and perceived in a consistent manner. However, both these concepts collapse all emotional reactions into a single uniform dimension, and despite being descriptive and operational for certain purposes, they seem unlikely to contribute to a deeper understanding of emotions in music.

Finally, we consider the evaluation of tension-either in music or as an experienced emotion-attractive due to its links with mood (POMS by McNair, Lorr, \& Droppleman, 1981), physiological measurements (i.e., muscle tension), prevalence in everyday descriptions of musical expressivity (Juslin \& Laukka, 2004), and apparent relevance to music theoretical discourse (Meyer, 1956; Lerdahl, 2001). However, tension has also been observed to correlate highly (negatively) with valence (Eerola \& Vuoskoski, 2011; Krumhansl, 1997). Also, the drawback of most studies on tension has been the lack of a common conceptual background.
Exceptions to this are the studies by Ilie \& Thompson (2006), implementing the three-dimensional emotion model proposed by Schimmack and Grob (2000), and Zentner and his colleagues (2008). The latter relates to the realm of music-specific emotions, summarized next.

Music-specific models. Though only a minority of studies (19) have employed music-specific emotion models, the results are of special interest since-as the emotion models are especially constructed for musical purposes - these studies avoid some of the criticisms levelled at the emotion concepts mentioned above. Hevner's (1936) ordering of emotions along the circumference of a circle was the first music-specific model that was further elaborated by several authors in subsequent years (e.g., Farnsworth, 1954; Wedin, 1972). Contemporary formulations of music-specific emotions have all suggested substantially more factors to emotional experiences than those offered by popular dimensional models. Asmus (1985) provided 9 dimensions, while Juslin offered over 15 emotions that exceed prevalence of $70 \%$ (Juslin \& Laukka, 2004; see also Juslin, Liljeström, Västfjäll, Barradas, \& Silva, 2008; Laukka, 2007), and Zentner settled on nine emotion factors that may also be collapsed into three metafactors (Zentner et al., 2008). Encouragingly, these recent music-specific models share many factors (feeling moved, nostalgic, relaxed, enchanted), and offer uniquely aesthetic emotions.

The most important observation from these studies is that the emotions induced by music are largely different from those usually studied under the label of basic emotions or the common dimensional models. Even if some of the emotions in the music-specific models are labelled in the same way as in the common discrete models, musical versions of these emotions seem to have a different character. For example, sadness in music is not usually associated with the aversive aspects of the emotion such as feeling gloomy, depressed, or unhappy (Laukka, 2007; Zentner et el., 2008). Note that the situation seems to be more straightforward in expressed emotions since no evidence has been provided that music-specific emotions would be easier to perceive or express in musical performances than the common discrete emotions.

\section{RESEARCH APPROACHES: A SUMMARY OF THE RESULTS}

Theoretical approaches. Theoretical approaches have mainly acted as a catalyst, serving the field as a test bed of ideas (e.g., Gabrielsson, 2002; Juslin et al., 2001; Konečni, 2008; Schubert, 1996; Sloboda, 2001), promulgating concepts from other fields (e.g., London, 2001; Panksepp, 1992; Scherer, 2004), or providing meta-analyses (Juslin 
\& Laukka, 2003; Västfjäll, 2002). The latter studies aside, perhaps the most influential theoretical studies have focused on specific, theoretical problems such as the dilemma of felt vs. perceived emotions (Gabrielsson, 2002), enjoyment of negative emotions (Schubert, 1996), and the proposal regarding a variety of mechanisms through which music may induce emotions (Juslin \& Västfjäll, 2008). These studies have all dealt with topics that seem to operate differently from mainstream emotion psychology. Somewhat surprisingly, studies that bring insights from non-music topics do not seem to have made such an impact on this field (e.g., many of Scherer's studies). It needs to be said that regarding the theoretical aspects of music and emotions, the handbook of music and emotions by Juslin and Sloboda (2001) is probably the most influential theoretical source and certainly the most cited reference in papers published after 2001.

Self-report approaches. The self-report approach has provided the cornerstone of the results in music and emotion research. It is the only way the listeners themselves can actively characterize their own, subjective emotional experiences. The dominant self-report measure has been the rating of an emotion construct on a Likert scale, which-depending on the construct measured-is known to produce reliable estimates of emotions across participants (e.g., Juslin, 1997a, 1997b). The results obtained in this manner are also linked with the affects acquired with more openended response formats such as adjective choices and free responses (Juslin, 1997a; Schubert, 2003).

The drawbacks of the self-report approach have rarely been questioned and it is more customary to see selfreports as a baseline to which physiological, acoustical, or neural measured are being compared. Most of the self-report measures are reduced verbalizations of the emotional experience-though exceptions such as similarity judgements exist-which are subject to limitations such as demand characteristics, and limitations in one's awareness and ability to explain emotions. The forced-choice paradigm is also a potentially valid selfreport method provided that the biases related to choosing between a finite set of categories (i.e., guessing, representation of mixed emotions) are overcome.

Biological approaches. The biological approach has concretely demonstrated that if the emotions are sufficiently different (i.e., sadness, happiness, anger, or distinct quadrants of the affect space), musically induced emotions do lead to discriminable physiological and neural patterns. At the physiological level, high arousal is related to respiratory activity (Nykliček et al., 1997) and perspiratory activity (Rickard, 2004). Differences in emotional valence may be differentiated by the activation of various facial muscles (Witvliet \& Vrana, 2007), including the startle reflex (Roy et al., 2008). However, these observations are often conflicting and indeterminate (for example, Etzel et al., 2006; Nater, Abbruzzese, Krebs, \& Ehlert, 2006), if not downright trivial concerning the generic arousal dimension. When the focus of an emotion study is on strong responses, it has become customary to record chill reactions (Blood \& Zatorre, 2001; Grewe et al., 2007a) in order to verify the temporal locations and the existence of such experiences in participants.

Studies measuring neural responses have documented the areas that are involved in emotional processing by investigating musically induced emotions in healthy participants (Blood \& Zatorre, 2001; Koelsch et al., 2006). Several studies have corroborated the discrimination of differentially valenced emotions by means of neural responses, as different cortical lateralization patterns emerge in response to positive and negative musical stimuli (Altenmüller et al., 2002; Flores-Gutierrez et al., 2007; Schmidt \& Trainor, 2001). In our view, the most intriguing contributions have come from studies with brain-damaged patients, showing selective emotional impairments concerning with, for example, the processing of fear (Gosselin, Peretz, Johnsen, \& Adolphs, 2007), implying specificities in the emotional processing of music. The most influential ${ }^{1}$ neurological study on music and emotions has undoubtedly been the one that likened the emotional and rewarding effects of preferred, chill-inducing music with strong, euphoriainducing stimuli such as food, sex, and drugs (Blood \& Zatorre, 2001), and it seems to have generated a series of chill-inducing studies in its wake.

The use of biological measures has become frequent, but the analysis methods and self-report methods have not developed at the same pace. For instance, many of the studies involving peripheral and neural measures reduce the data into static segments - compatible with static self-report measures - instead of capturing the dynamic aspects of music-induced responses that would require more sophisticated time-series analyses (see Korhonen, Clausi, \& Jernigan, 2006).

Developmental approaches. The developmental approach has documented the ages at which children are able to detect particular emotions in music, and the emotional cues they are responsive to at each point of

\footnotetext{
${ }^{1}$ Cited 256 times in ISI Citation Index, which is above the other neuroscience papers concerning music and emotions, e.g., Peretz et al. (1998): 86; Koelsch et al. (2006): 75; Brown et al. (2004): 48; Gosselin et al. (2005): 36; Khalfa et al. (2002): 33; Altenmüller et al. (2002): 22.
} 
their development. This approach has also been important in highlighting the aspects of emotions that are the least culture-dependent. Sensitivity to emotional communication is thought to be present in early infancy due to the importance of caregiver emotion communication via speech and singing (Trehub \& Nakata, 2001), and this claim is supported by some empirical findings (Nawrot, 2003). Most developmental studies have focussed on the preschool years, describing the ability to distinguish an increasing range of basic emotions using forced-choice paradigms with pictorial representations of emotion categories. The results suggest that, around the age of four, children are able to recognize happiness and sadness in music (Cunningham \& Sterling, 1988), as well as anger and fear (Boone \& Cunningham, 2001), although these latter emotions are still frequently confused by older children and even by adults (Dalla Bella et al., 2001; Robazza, Macaluso, \& D’Urso, 1994; Terwogt \& Van Grinsven, 1991). Throughout their development, children begin to apply more and more style-specific musical cuessuch as mode (major-minor) division-in determining the appropriate affect (Dalla Bella et al., 2001; Kastner \& Crowder, 1990).

Cross-cultural and individual approaches. The crosscultural and individual approaches are both rare, but the extant cross-cultural studies have demonstrated that at least the broad, discrete categories of emotions (happy, sad, and scary expressions in Fritz et al., 2009, and joy, sadness, and anger in Balkwill \& Thompson, 1999) are communicated across cultures, mirroring the findings of cross-cultural speech expression recognition studies (e.g., Scherer, Banse, \& Wallbott, 2001). The underlying reasons for the successful communication have been expressed by means of a cue redundancy model (Balkwill \& Thompson, 1999), which postulates that a set of psychophysical as well as culture-specific cues account for emotions.

The cross-cultural approach is an extremely powerful way of looking at the division between universal and cultural associations regarding music and emotion. Having said that, such studies are particularly challenging to carry out in a convincing way. Most of these studies focus on emotion recognition, probably because of the same challenges that are also present in developmental studies where forced-choice paradigms and pictorial representations of emotions are utilized in order to avoid verbal descriptions. In cross-cultural studies, a more important concern is the conceptual equivalence of the studied emotional concepts as well as translation issues, which may both lead to unfounded comparisons. Also, it is nearly impossible to find participants in the contemporary world who would not have any prior exposure to Western music. In this sense, the study by Fritz and colleagues (2009) that featured Mafa listeners from remote settlements in the North Province of Cameroon can be considered invaluable.

The studies utilizing an individual approach to emotions have sought to assess the role of musical expertise, gender, or personality traits in emotion recognition or experience. Most studies have failed to find major differences in emotional processing stemming from musical expertise or gender (Bigand et al., 2005; Frego, 1999; Juslin, 1997c; Kreutz, Bongard, \& Von Jussis, 2002), although exceptions to this observation exist (Fredrickson, 1995; Hoshino, 1996), particularly concerning psychophysical reactivity in men and women (Nater et al., 2006). The stable personality traits of listeners have been observed to influence emotional reactions in ways predicted by such theoretical assumptions as trait-congruency (i.e., individuals preferentially process stimuli that are emotionally congruent with their personality traits; see e.g., Kallinen \& Ravaja, 2004; Vuoskoski \& Eerola, 2011). To date, studies investigating individual factors have been limited to prevalent emotion models (basic emotions, or valence and arousal), and the role of individual factors has been moderate in comparison with the overall emotion recognition accuracies. In future studies, it would be interesting to investigate the extent to which overall emotional intensity, tendency to represent emotions with precision and specificity (Tugade, Fredrickson, \& Barrett, 2004), and everyday uses of music are linked with individual factors.

Music analytic approaches. The music analytic approach has documented the wide range of reliable cues that characterize emotions in music. Production studies-which can be divided into studies of emotional expressivity (Juslin, 1997c; Laukka \& Gabrielsson, 2000) and composition (e.g., Thompson \& Robitaille, 1992; Vieillard et al., 2008) - have produced the largest impact on our understanding of the features related to emotions. A stream of analytical studies, where emotioninducing music-verified by self-reports-is dissected into its constituents by means of acoustic and musical analyses or rating studies (e.g., Leman et al., 2005; Schubert, 2004) have reinforced the results of the production studies. From all of these studies, systematic couplings between musical features and particular emotions have been established. For instance, happy expression is achieved by fast voice onsets, bright timbre, major mode, and fast tempo, whereas anger has otherwise similar features but loudness tends to be higher and the 


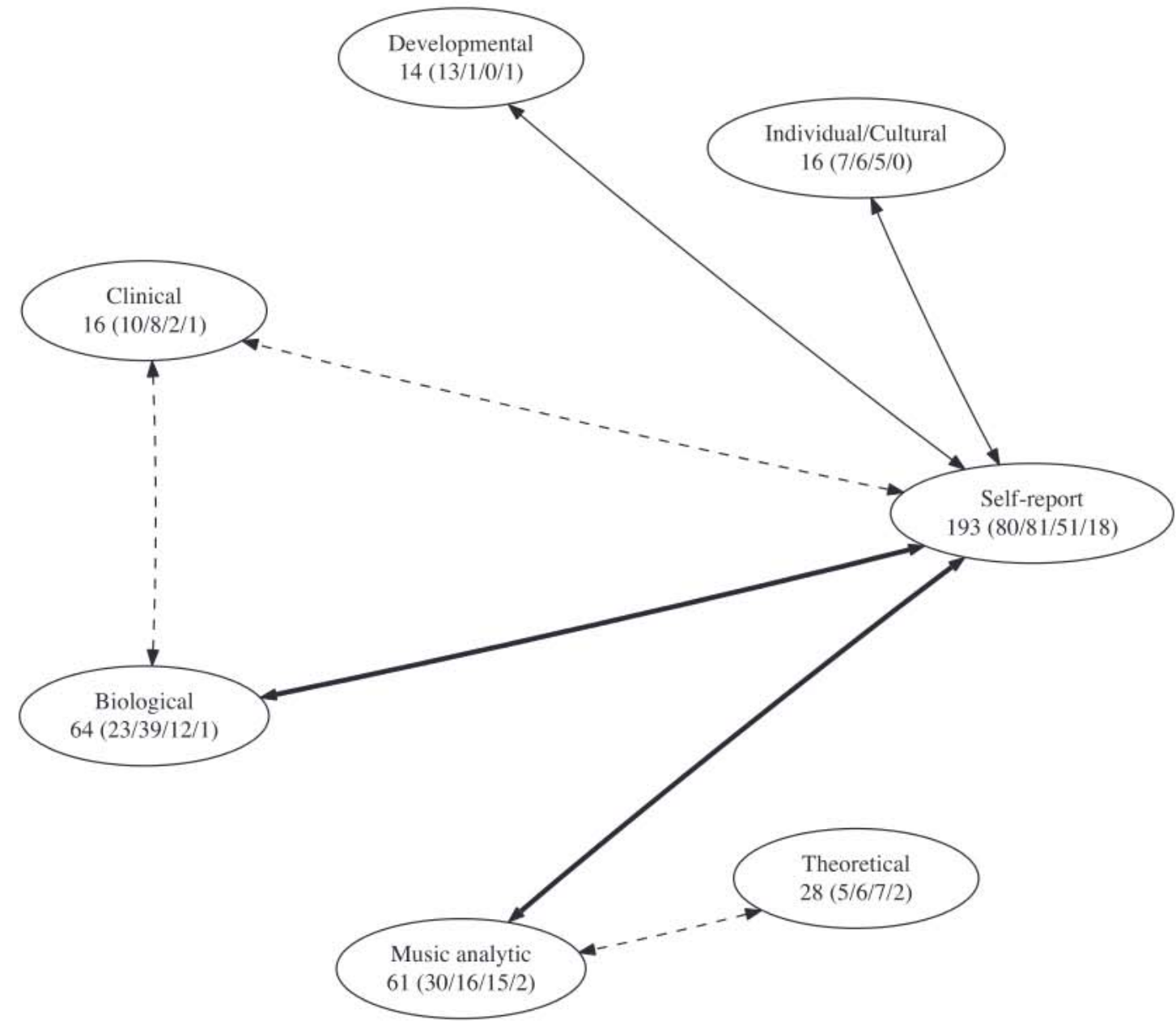

FIGURE 1. A summary of the approaches and emotion models (discrete/dimensional/ miscellaneous/music-specific) in reviewed studies. The connectors display the prevalence of concurrent approaches, where the bold lines denote > 20 studies, solid line > 10 studies, and dashed line $>5$ studies.

microstructure more irregular (cf. Gabrielsson \& Lindström, 2010). Direct manipulations of the central features such as tempo, mode, and register have corroborated their role in music and emotions (Ilie \& Thompson, 2006; Juslin, 1997c).

Despite the extensive, detailed reports of the featureemotion couplings, the scope of the studies has largely remained neutral in terms of musical style (no particular style or resemblance to film soundtracks or classical music). A great deal of further research is needed in order to establish underlying similarities of these couplings across a larger variety of musical styles. Also, the music analytic approach has been too rarely used in conjunction with other approaches, despite the direct gains such an approach could bring to the generalizability of the findings.
PREVALENCE OF RESEARCH APPROACH, EMOTION MODEL, AND LOCUS OF EMOTION IN ALL STUDIES

To highlight the broad trends in an effective manner, compact summaries depicting every research approach, locus of emotion, and emotion model are first presented in graphical form. The references for the studies that belong to each category are given in the appendix (Tables A1-A7 in the Appendix).

Figure 1 displays a simplified quantitative summary of studies falling into the chosen seven research approaches as well as the prevalence of the simultaneous usage of several approaches in a single study. For instance, more than ten self-report studies have collected data relevant for the individual and cultural differences approach category. The numbers in brackets refer to the number of each kind of emotion model used 
TABLE 1. Cross-Tabulation of Emotion Models (Rows), Approaches (Columns), and Locus of Emotion (in Subscripts - Felt/Perceived/Both).

\begin{tabular}{|c|c|c|c|c|c|c|c|c|}
\hline & Self-R. & Biol. & Mus A. & Theor. & Clin. & Ind./Cul. & Dev. & $\%^{*}$ \\
\hline Discrete & $80_{16 / 65 / 3}$ & $23_{8 / 10 / 5}$ & $30_{1 / 26 / 3}$ & $5_{2 / 3 / 1}$ & $10_{1 / 9 / 1}$ & $7_{2 / 5 / \square}$ & $14_{\square / 14 / \square}$ & $38 \%$ \\
\hline Dimensional & $81_{40 / 45 / 4}$ & $39_{26 / 13 / 1}$ & $16_{4 / 13 / \square}$ & $6_{3 / 3 / 1}$ & $8_{1 / 7 / 1}$ & $6_{5 / 1 / \square}$ & $1_{\square / 1 / \square}$ & $35 \%$ \\
\hline Misc. & $51_{24 / 17 / 12}$ & $12_{8 / 2 / 2}$ & $15_{9 / 3 / 4}$ & $7_{4 / 1 / 2}$ & $2 \square / 2 / \square$ & $5_{3 / 1 / 1}$ & & $21 \%$ \\
\hline Music-specific & $18_{6 / 11 / 4}$ & $1_{1 / 1 / \square}$ & $2_{\square / 2 / \square}$ & $21 / 1 / 1$ & $1_{\text {/口/口/1 }}$ & $0_{\square / \square / \square}$ & $1_{\text {/ロ/1/ロ }}$ & $6 \%$ \\
\hline$\frac{\circ}{8} *$ & $52 \%$ & $17 \%$ & $14 \%$ & $5 \%$ & $5 \%$ & $4 \%$ & $3 \%$ & \\
\hline
\end{tabular}

*Proportion of total studies refers to number of studies directly classified according to research approach, and may differ from the row/column totals as all the studies do not report the exact model utilized, and the several approaches and models may be used simultaneously.

within each research approach in the following order: discrete/dimensional/miscellaneous/music-specific.

What is interesting in the visualized cross-tabulation of the research approaches and emotion models in Figure 1, is that while the self-report approach has been the most common ( $77 \%$ of the studies), two other approaches are equally common (biological and music analytic, each about one quarter of the studies). The self-report approach is probably slightly different in nature compared to the other approaches, as it is the hub upon which all other approaches rely in order to validate that participants were actually experiencing the intended emotions (when the measurements are biological). It must also be said that the link between theoretical studies and other approaches should be regarded in a special way, since all empirical studies have made use of theoretical approaches in their study designs and hypotheses. Hence, the three studies showing explicit, concurrent use of theoretical and self-report approaches may be considered as exceptions; two-part articles with the main emphasis on the theoretical section and a proof of concept given in a shorter empirical section (e.g., Holbrook \& Anand, 1992; Juslin \& Laukka, 2004; Madsen, 1997a).

It is worth noting that special populations (featured in clinical, developmental, and individual and cultural differences approaches) are rarely combined with anything other than self-report approaches, probably due to their reliance on special populations. Also, biological approaches combined with individual and cultural differences are relatively scarce because of the specificity of the questions involved as well as for practical reasons (for example, a field study in an isolated geographical location with a non-Western influenced population would not have easy access to a MEG recording device).

Figure 1 gives a fairly uniform message that the discrete and dimensional models remain the two most prevalent emotion models in music and emotion research. In the studies using self-report and clinical approaches, these two models are equally common, but in developmental and biological studies the balance is somewhat different. In developmental studies, children are typically asked to choose a suitable facial expression from the two or three candidates offered to match the emotion expressed by music, and hence the emotion model is typically discrete (happy/sad). In biological studies the underlying physiological mechanisms involved are often characterized using valence and arousal (with physiological or neurological explanations pointing towards avoidance and approach systems), thus directing the choice of emotion model towards the dimensional. The miscellaneous and music-specific emotion models are almost equally dispersed among the variety of research approaches, suggesting that these models can easily accommodate different methodological and conceptual approaches.

The prevalence of emotion models across all studies and how often they are used simultaneously in a single study is shown in Table 1 . The two dominant (70\%) emotion models, discrete and dimensional, are used almost equally frequently, and both are used in the same study in about $10 \%$ of the studies utilizing these models. This seems to be a recent trend, as most of the studies combining discrete and dimensional models are published after the year 2004 (see Figure 2 for the details of the temporal trends). As such, the use of two different emotion models in the same study might reflect the need to compare the models, or it may be seen as a sign of acceptance that emotions may easily be conceived as both belonging to discrete categories while also representing a dimensional continuum. Also, the number of studies (14) not specifying the locus of emotion mostly reflect the era before the issue was made explicit by Gabrielsson (2002) and Sloboda (2001), since a large proportion $(57 \%)$ of these studies predate these two landmark studies. Although the combined use of music-specific and traditional emotion models in the same study is not common, the miscellaneous models co-occur with the dimensional models in 15 studies. These studies often collect valence or arousal ratings, 

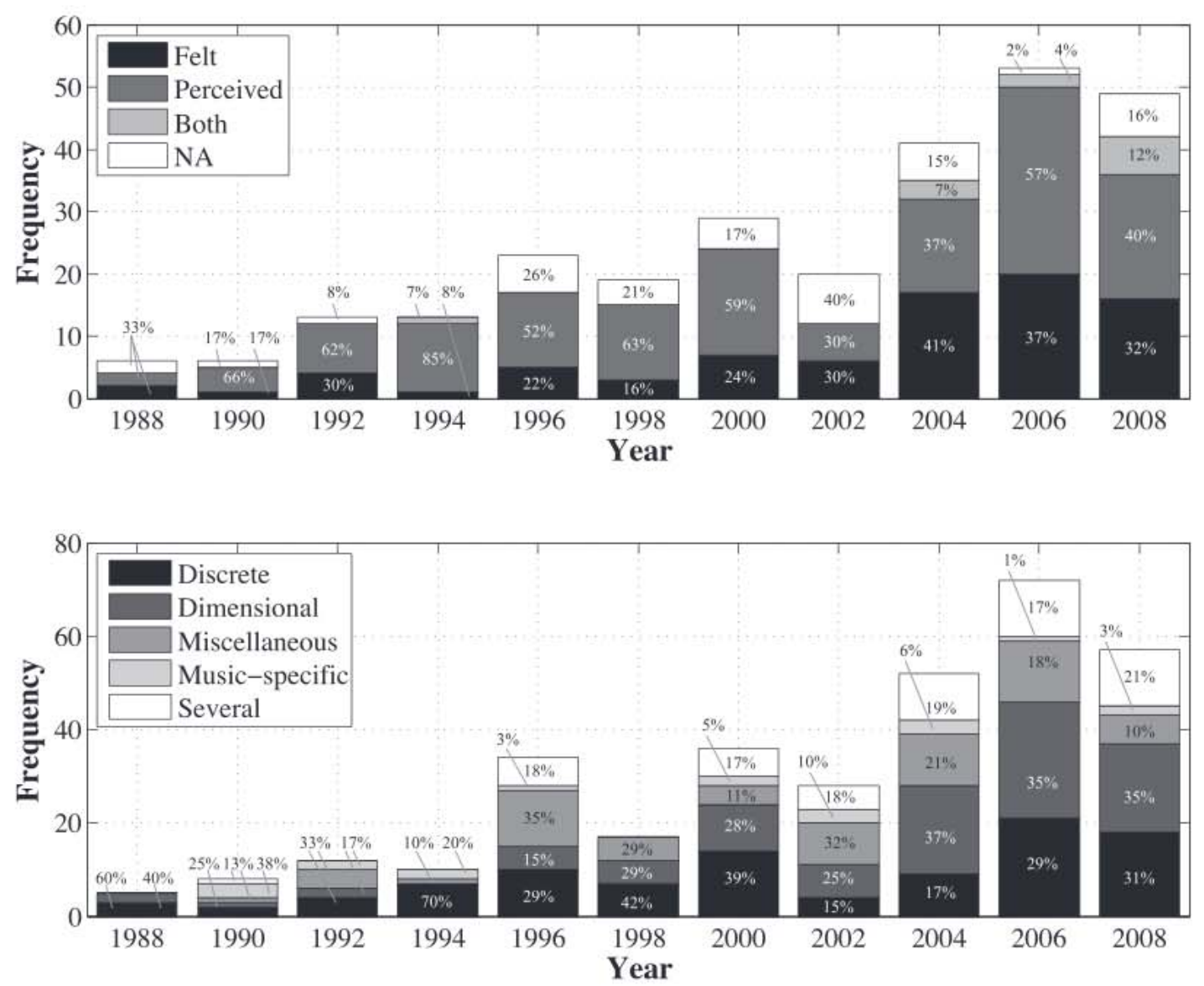

FIGURE 2. Temporal trends of the locus of emotion (upper panel) and emotion models (lower panel). The percentage for each category is also displayed to allow better differentiation from the yearly increase of the pertinent studies.

liking, or preference ratings (Brown et al., 2004; Rawlings \& Leow, 2008), and mood (Husain et al., 2002) or intensity ratings (Kreutz et al., 2008).

Miscellaneous models are the third most common of the four categories, and within these models, emotional intensity, preference, and tension are the most common choices for alternative self-report concepts. Musicspecific models are only featured in 19 of all 251 studies, but if we look at these studies in detail, we notice that only a few influential music-specific emotion models have been proposed over the years. The first one is Wedin's (1972) model, which consists of three bipolar factors (gaiety - gloom, tension - relaxation, solemnity - triviality). This model was used by only one of the studies we looked at (Giomo, 1993). The second formulation of a music-specific emotion model was made by Asmus (1985), who settled for nine affective dimensions that have been used by at least three studies over the past 20 years (Coffman, Gfeller, Eckert, 1995; Gfeller \& Coffman, 1991; Gfeller, Asmus, \& Eckert, 1991). The third music-specific emotion model was offered by Bartel (1992) and contained 12 bipolar dimensions. Recent surveys of emotion terms associated with music (Juslin \& Laukka, 2004; Juslin et al., 2008; Lindström, Juslin, Bresin, \& Williamon, 2003; Scherer, Zentner, \& Schacht, 2002; Zentner et al., 2008) have greatly enlarged the scope of emotion concepts available for contemporary researchers. From this literature, the Geneva Emotional Music Scale (GEMS) by Zentner and his colleagues (2008) may be the most easily approachable and the most systematically constructed.

In terms of the locus of emotion, dimensional, miscellaneous, and music-specific models are evenly distributed between emotions that are felt and perceived in music. For discrete emotion models, there seems to be an emphasis towards a perceived locus of emotion, probably due to the emotion recognition tasks that are popular in all developmental, cross-cultural, and some biological studies (Table 1). It is also worth noting that there has been a shift in focus during the last 6-8 years 
TABLE 2. Summary of Research Approaches and Emotion Loci in Journal Articles Addressing Music and Emotions During the Last Two Decades.

\begin{tabular}{|c|c|c|}
\hline & Felt Emotions & Perceived Emotions \\
\hline \multicolumn{3}{|c|}{ Methodological Approach } \\
\hline Self-report & Juslin \& Laukka (2004); Konečni et al. (2008) & Juslin (1997c); Ritossa \& Rickard (2004) \\
\hline Biological & Blood \& Zatorre (2001); Witvliet \& Vrana (2007) & $\begin{array}{l}\text { Khalfa, Roy, et al. (2008); Peretz, Blood, Penhune, } \\
\text { \& Zatorre (2001) }\end{array}$ \\
\hline Music analytic & Sloboda (1991) & Schubert (2004) \\
\hline Theoretical & Scherer (2004); Sloboda (2001) & Scherer (1995) \\
\hline Clinical & Khalfa, Delbe, et al. (2008) & $\begin{array}{l}\text { Dellacherie et al. (2008); Nielzen, Olsson, \& } \\
\text { Öhman (1993) }\end{array}$ \\
\hline Individual differences & Kallinen \& Ravaja (2004); Nater et al. (2006) & Rawlings \& Leow (2008) \\
\hline Developmental & - & $\begin{array}{l}\text { Dalla Bella et al. (2001); Terwogt \& Van Grinsven } \\
\text { (1991) }\end{array}$ \\
\hline \multicolumn{3}{|l|}{ Emotion Model } \\
\hline Discrete & Baumgartner et al. (2006); Krumhansl (1997) & Juslin (1997a); Kallinen (2005) \\
\hline Dimensional & $\begin{array}{l}\text { Grewe et al. (2007a); McFarland \& Kennison } \\
\quad(1989 a)\end{array}$ & Gagnon \& Peretz (2000); Ilie \& Thompson (2006) \\
\hline Miscellaneous & Bigand et al. (2005); Thaut \& Davis (1993) & Brittin \& Duke (1997); Frego (1999) \\
\hline Music-specific & Dibben (2004); Zentner et al. (2008) & Bartel (1992); Gfeller et al. (1991) \\
\hline
\end{tabular}

from emotion perception towards music-induced, experienced emotions. This historical continuum has been visualized in Figure 2, which displays temporal histograms of the publication years of the studies divided according to the locus of emotion (upper panel) and emotion model (lower panel). The locus of emotion panel displays a slight positive trend towards the simultaneous investigation of felt and perceived emotions over the last five years. As previously mentioned, this applies equally to all emotion models: Figure 2 shows that using several emotion models in one study has also become more common recently. And finally, the prevalence of both miscellaneous and music-specific models of emotion has increased during the last 6 years, although no sudden emergences of a particular model are apparent.

\section{SUMMARY OF POPULAR THEMES}

To bring together the results regarding the prevalence of each research approach, emotion model, and locus of emotion, a cross-tabulated listing of these components is shown in Table 1 . The first number in each cell indicates the number of studies corresponding to each research approach (column) as combined with each emotion model (row). The small numbers separated by forward slashes stand for the locus of emotion. They indicate the number of studies falling into one of three categories of locus of emotion (felt, perceived, both). The full breakdown of the studies, indicated in Table 1 , is given in the appendices (A1-A7).
The summary underlines the dominance of selfreport approaches ( $\square 80 \%$ of studies) that use discrete $(43 \%)$ and dimensional (43\%) emotion models. In general, the locus of emotion is evenly divided between felt and perceived, although the prevalence varies between research approaches and emotion models. Variations in the balance between felt and perceived emotions are to be expected, as the studies that emphasize biological approaches typically focus on felt emotions, and-due to limited instructional possibilities-developmental studies have to rely on emotions that are perceived or recognized by children. Also, within the discrete model for emotions, perceived emotions have been favored due to an emphasis on the recognition of emotion categories. To give the reader a few textbook examples of studies that reflect each research approach, emotion model, and locus of emotion, two example studies for each approach (7) and emotion model (4) are given for each locus of emotion (2) in Table 2. The example studies have been selected to represent a variety of years, and provide recommended reading for those interested in such approaches.

MUSICAL STIMULI

Table 3 encapsulates selected details about the stimuli used in music and emotion studies. Note that many studies did not use any stimuli (or the reported details were not accurate enough), and hence the table only shows details from 170 of the 251 studies. Regarding the question of musical genre, it was no surprise to discover 
TABLE 3. Summary of Stimulus Details From a Subset of Studies ( $N \square$ 170).

\begin{tabular}{lc}
\hline & Frequency (\%) \\
\hline Genre & \\
Classical & $82(48 \%)$ \\
Mixed & $27(16 \%)$ \\
Pop/Rock & $5(3 \%)$ \\
Ethnic & $6(4 \%)$ \\
Film music & $3(2 \%)$ \\
Custom-made & $18(11 \%)$ \\
N/A & $29(17 \%)$ \\
Nature of stimuli & \\
Commercial recordings & $115(76 \%)$ \\
Custom-made & $37(24 \%)$ \\
Chosen by & \\
Researchers & $57(33 \%)$ \\
Pilot study & $14(8 \%)$ \\
Previous study & $16(9 \%)$ \\
Panel/Expert group & $10(6 \%)$ \\
Participants & $7(4 \%)$ \\
N/A & $43(39 \%)$ \\
\hline
\end{tabular}

that classical music is still the dominant genre (prevalence $48 \%$ ), as confirmed by a previous meta-analysis ( $41 \%$ in Juslin \& Laukka, 2003). This was also observed to be the prevalent musical style in a meta-analysis of musical mood-induction studies by Västfjäll (2002, p. 176). Almost a fifth of the studies use several genres (often three separate styles such as classical, pop, and film music). In these cases, the stimulus selection is characterized either by such broad terms as "drawn from the corpus of Western music" (Gomez \& Danuser, 2004), or by being selected from different musical styles to elicit different types of emotional responses (Ali \& Peynircioğlu, 2006; Nater et al., 2006), or deliberately "to make the results as general as possible" (Hunter, Schellenberg, \& Schimmack, 2008). Despite the increased number of studies using mixed genres, it seems that further work is needed in this area, as emotional reactions may differ across genres due to their inherent musical differences (i.e., the functions of music; e.g., Zentner et al., 2008). It has also been discovered that music preferences influence felt and perceived emotions (Kreutz et al., 2008). It is somewhat surprising that many popular genres such as $\mathrm{R} \& \mathrm{~B} /$ soul, dance, or chart pop are featured rarely or not at all in the studies on music and emotion (see Eijck, 2001; Mulder, Ter Bogt, Raaijmakers, Gabhainn, \& Sikkema, 2009; North, Hargreaves, \& Hargreaves, 2004).
NATURE OF THE STIMULI: COMMERCIAL RECORDINGS VERSUS CUSTOM-MADE EXAMPLES

The majority of the studies reviewed (75\%) used excerpts of real, commercially recorded music, which at least dispels some of the notions of musical examples being artificial and contrived. It should be kept in mind that real and synthetic stimuli are typically used for entirely different purposes. While the use of real excerpts keeps the ecological validity high, such examples lack the control of musical and acoustical parameters. In this respect, artificially manipulated stimuli allow the researcher to probe into predefined musical factors (such as register, mode, tempo, and volume) in a controlled manner. To make matters more complicated, precise control of musical features is not always guaranteedeven when synthetic stimuli are employed-if the manipulation scheme does not follow strictly defined factorial parameterization of the chosen features.

Custom-made or synthetic stimulus materials are often composed to sound natural to the listeners (e.g., the Montreal Battery, Peretz et al., 1998, addressed in detail later), and such a creation principle will probably not include systematic, factorial manipulation of musical parameters that would have enabled the researcher to study the role of each manipulated feature separately. In fact, systematic manipulation is usually not a common tactic in music and emotion research. The structural parameters of music have been manipulated in terms of their symbolic representations by only a few researchers (e.g., Dalla Bella et al., 2001; Gagnon \& Peretz, 2003), and likewise only a few studies have manipulated performance features (e.g., tempo, register, loudness) in terms of the audio representation of real music recordings (Ilie \& Thompson, 2006; also indirectly by Hunter et al., 2008). Hybrid forms of stimuli, where the actual performances of simplified musical materials (typically melodies with varying emotional expression) are recorded, exist, and are used in emotion recognition tests. In most production studies, high-level professional musicians have been asked to perform simple melodies or rhythmic patterns in different ways to express happiness, sadness, and tenderness (Gabrielsson \& Juslin, 1996; Gabrielsson \& Lindström, 1995; Juslin, 1997c, 2000; Laukka \& Gabrielsson, 2000; Timmers \& Ashley, 2007). Variants of the task have invited children to sing tunes with different emotional expressions (Adachi \& Trehub, 1998, 2002), or composers to create suitable music to befit the emotional expression supplied by the researcher (Thompson \& Robitaille, 1992). The production tasks in such custom-made samples provide a compromise between high control and musical naturalness, and certainly this approach could 
be more commonly used in music and emotion studies (cf. emotions expressed in speech, Banse \& Scherer, 1996; Cowie \& Cornelius, 2003).

\section{STIMULUS SELECTION}

The typical method of selecting the stimuli within the field of music and emotion research has almost entirely been researcher-driven: either the authors have intuitively selected the stimuli (33\%), a pilot study has been used, a panel or group of experts has selected the stimuli, or they have been chosen on the basis of a previous study $(8 \%, 6 \%$, and $9 \%$, respectively). In a minority of the studies $(4 \%)$, participants have been allowed to choose the musical material themselves. This naturally reflects the requirement to control the stimulus material, and the specific aims of individual studies to focus on certain emotion models and approaches. To put it in a simpler way: it makes sense to select arousing and non-arousing music for a study that aims to determine the extent to which emotional arousal induced by music could be detected from peripheral measures (e.g., Nater et al., 2006; Nykliček et al., 1997), rather than to ask participants to bring their own music. However, an interesting but rare addition to such a tactic is to use participant-chosen music in addition to researcherchosen music (Rickard, 2004), or to use only strongly emotional music chosen by the participants themselves (Blood \& Zatorre, 2001).

The method of stimulus selection has undoubtedly the largest impact on studies investigating felt emotions. Music-induced emotions can be regarded as personal, and they depend more on individual issues such as learning, associations, and musical taste than the recognition of emotions in music (Juslin \& Västfjäll, 2008). As mentioned previously, in medically oriented studies of pain and stress reduction (Pelletier, 2004), it has been demonstrated that self-chosen music in general is more efficient in modulating one's own mood than researcher-chosen music (also in MacDonald et al., 2003). Similar observations have been reported in studies that have aimed to investigate and record strong emotional experiences induced by music (e.g., Blood \& Zatorre, 2001; Rickard, 2004). This-coupled together with the notion that contemporary audio analysis and manipulation tools such as the MIR toolbox (Lartillot \& Toiviainen, 2007) or the Sonic Visualizer (Cannam, Landone, Sandler, \& Bello, 2006) greatly facilitate controlling and describing participant-chosen music-means that the use of participant-chosen music is certainly a promising avenue for progress. Also, the widespread popularity of portable music devices and the way people use playlists will afford researchers new possibilities to capture everyday emotional experiences, and to relate them to the actual features of the music.

\section{STIMULUS QUANTITY}

We should now turn to the issues of stimulus quantity and duration, which are presented as histograms in Figure 3. The median number of stimuli in all studies is 10 , although the number varies substantially across studies (from 1 to $100 \square$, see the upper panel in Figure 3). While a large portion $(66 \%)$ of the studies employs less than 20 stimuli, there are also notable exceptions that use 60 or more stimuli. Probably the stimulus number itself is not always meaningful, as the design of the study and subsequently the overall length of the experimental session $(<60 \mathrm{~min})$ are the overarching constraints on the maximum number of stimuli used.

The typical stimulus duration, shown in the lower panel of Figure 3, shows a pattern similar to typical stimulus quantity (the upper panel): Short excerpts (with a median of $60 \mathrm{~s}, 35 \%$ of the studies used excerpts shorter than $30 \mathrm{~s}$ ) are widespread, although 1-, 2-, and 3-min examples are also used in about one third of the studies. As explained previously, stimulus duration depends heavily upon the predetermined study design, approach, and locus of emotion. For example, the median stimulus duration of the studies focusing on felt emotions is $90 \mathrm{~s}$ (with a mean of 135.4), while for studies focusing on perceived emotions this is $24 \mathrm{~s}$ (with a mean of 62.8). The issue here is whether or not the focus is on mere emotion recognition (perceived emotions), as this has been shown to be possible even when extremely short musical clips ( $1 \mathrm{~s}$ in Bigand et al., 2005; 3.5-5 s in Al'tman, Alyanchikova, Guzikov, \& Zakharova, 2000; $0.6 \mathrm{~s}$ in Goydke, Altenmüller, Moller, \& Munte, 2004) are used. When the focus is on emotion induction (felt emotions), the induction of an emotional response and the subsequent self-reporting of the experienced emotion may require more time. Judging from the typical stimulus durations used in studies investigating felt emotions, it seems that 30 to $60 \mathrm{~s}$ is enough. Except for the study by Altenmüller et al. (2002), which used 15-s excerpts, very few similarly focused studies have attempted to use excerpts shorter than 20-s. In direct contrast, the decision to choose reasonably short excerpts in most studies on perceived emotions reflects the fact that the most common research approach used in these studies is self-report (e.g., Likert ratings of the emotion concepts in question), which typically require the participant to give a single evaluation per excerpt. For this reason, the musical examples are chosen to be representative examples of a given emotion and do not contain large temporal variations. Some of the longest 

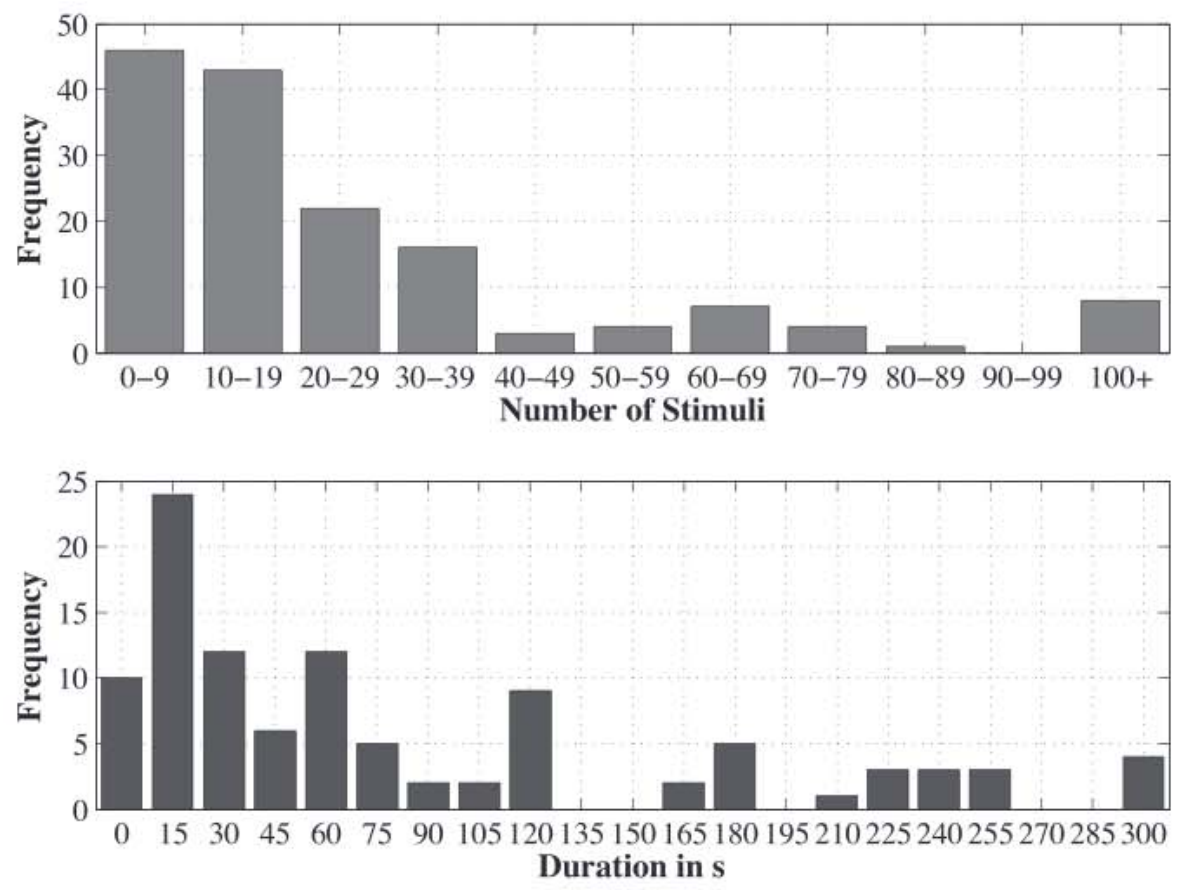

FIGURE 3. Stimulus quantities and durations in a subset of music and emotion studies ( $N \square 170$ ).

excerpts stem from studies that focus on the temporal aspects of emotions using a continuous rating method (McAdams et al., 2004; Schubert, 1999, 2003; Sloboda \& Lehmann, 2001).

To set the stimulus quantities of music and emotion studies in perspective, a comparison with affective stimulus sets in other fields, such as the visual domain, is worthwhile. The International Affective Picture System (IAPS) uses 12 series of 60 pictures each (Lang, Bradley, \& Cuthbert, 1999), out of which typical emotion studies tend to use 50-60 images (a median in a sample of 20 studies using IAPS). In comparison, the amount of stimuli used in music-related studies is considerable lower than this (median of 10, 66\% used less than 20 stimuli). For emotions in speech, the stimulus sets tend to have a larger number of stimuli, and the excerpts are typically shorter (e.g., Burkhardt, Paeschke, Rolfes, Sendlmeier, \& Weiss, 2005; Douglas-Cowie, Campbell, Cowie, \& Roach, 2003).

\section{STIMULUS FAMILIARITY}

Prior exposure to (or familiarity with) the music used as stimulus material is a problematic factor for music and emotion studies, as associations to television commercials, films, or past events can shape the emotional experiences in unwanted or at least uncontrolled ways (Juslin \& Västfjäll, 2008). This issue is related to certain emotion induction mechanisms such as evaluative conditioning and episodic memories (Juslin \& Västfjäll, 2008). Familiarity also increases liking (Schellenberg, Peretz, \& Vieillard, 2008), and while that is a positive factor, familiarity may confound the results of a study if all participants are not equally familiar with the musical examples used. Thus, we assessed whether the participants of the reviewed studies were likely to have been exposed to the musical excerpts used. Although the issue of probable prior exposure cannot be objectively determined afterwards, we will offer examples of wellknown pieces of music that we think typical, educated participants might be familiar with.

We were able to find 43 studies in which rather wellknown musical examples from the popular repertoire had been used. For example, Tomaso Albinoni's Adagio in $\mathrm{G}$ minor for Strings and Orchestra had been used in at least 16 studies. $^{2}$ Other popular choices have included Samuel Barber's Adagio for Strings, Gustav Holst's Mars - The Bringer of War, Modest Mussorgsky's Night on

\footnotetext{
${ }^{2}$ Dalla Bella et al. (2001); Gosselin et al. (2006, 2007); Khalfa, Delbe, et al. (2008); Konečni et al. (2008); Kreutz et al. (2008); Krumhansl (1997); Lesiuk (2005); Martin \& Metha (1997); Mitterschiffthaler, Fu, Dalton, Andrew, \& Williams (2007); Peretz et al. (2001); Peretz et al. (1998); Schellenberg, Nakata, Hunter \& Tamoto (2007); Tan, Spackman \& Bezdek (2007); Thompson, Schellengberg, \& Husain (2001).
} 
the Bare Mountain, Antonio Vivaldi's La Primavera from The Four Seasons, Wolfgang Amadeus Mozart's Eine Kleine Nacht Musik, Carnival of Animals by Camille Saint-Saens, parts from the Peer Gynt Suite by Edward Grieg, Giuseppi Verdi's Brindisi from La Traviata, Beethoven's Symphony No. 6, Blue Danube by Richard Strauss, Chanson du Toreador from Carmen by Bizet, Wolfgang Amadeus Mozart's Requiem (selected parts), and so on. A related issue is that many studies do not explicitly report the exact movements or segments used as stimuli, thus making their findings non-replicable.

Many of these aforementioned, well-known pieces are first used in one influential study (e.g., Krumhansl, 1997; Peretz et al., 1998) that gets cited in subsequent studies that are either inspired by the initial study (e.g., Gosselin et al., 2006; Khalfa, Roy, Rainville, Dalla Bella, \& Peretz, 2008), attempt to replicate some of the findings (e.g., Konečni et al., 2008), or want to rely on the safe musical choices established by a previous study (e.g., Baumgartner et al., 2006; Schubert, 2004; Zentner et al., 2008). The number of studies (42) featuring this popular repertoire is considerably high considering that there were only 81 studies with classical music recordings overall in the 251 reviewed studies. In the future, studies investigating music-induced emotion should avoid such overfamiliar stimulus materials, and hence reduce possible unwanted associations.

As pointed out in the above summary of the popular repertoire, there are relatively few originators of stimulus sets. Isabelle Peretz and her team in Montreal have been extremely active in emotion studies in general, and have launched two influential stimulus sets for music and emotion research. The first contains 32 classical music excerpts (Peretz et al., 1998) consisting of recordings of the popular classical repertoire (both orchestral and solo piano works), most of which have worked their way into a host of subsequent studies. ${ }^{3}$ The second set, called the Happy, sad, scary and peaceful musical excerpts for research on emotions (Vieillard et al., 2008; documented also in Gosselin et al., 2005), consists of 56 specifically composed, MIDI-generated synthetic examples divided into four discrete emotion categories (happy, sad, scary, and peaceful), which have been used in at least nine studies to date. ${ }^{4}$ In mood induction studies, some early authors (e.g., Albersnagel, 1988;

\footnotetext{
${ }^{3}$ Dalla Bella et al. (2001); Fritz et al. (2009); Gosselin et al. (2007); Khalfa et al. (2002); Peretz \& Gagnon (1999); Schellenberg et al. (2008).

${ }^{4}$ Dalla Bella et al. (2001); Gosselin et al. (2005, 2006, 2007); Khalfa et al. (2002); Khalfa, Delbe, et al. (2008), Peretz \& Gagnon (1999); Peretz et al. (2001); Schellenberg et al. (2008); Vieillard et al. (2008).
}

Clark \& Teasdale, 1985) have also created stimulus sets that have been used by a large number of subsequent studies (see Västfjäll, 2002, for details).

\section{CONTEXTUAL AND METHODOLOGICAL ISSUES}

Although we did not develop a coding for the contextual aspects of music and emotion studies, some of these may be briefly outlined in order to complete the picture of the state of research. Almost all of the 251 studies reviewed have been conducted in laboratory settings. In a typical study, participants individually listen to and rate the musical examples using headphones and a computer interface. Such situations are probably not the most conducive to emotion induction, but such a controlled environment also ensures effective comparability between listeners. We do not see the laboratory experiments as problematic for perceived emotion studies, as emotion recognition is probably little affected by the artificiality of the music listening situation. Only a few studies have used more realistic contexts (mainly survey studies; Juslin \& Laukka, 2004; Zentner et al., 2008), but the bolder attempts to measure emotions outside the laboratory are worth mentioning, as they have led to a new form of the self-report approach. For example, Vaitl, Vehrs, and Sternagel (1993) had listeners rate their emotional arousal while listening to selected leitmotifs from Wagner's operas during the Bayreuth Opera Festival. This idea was extended by McAdams et al. (2004) by inviting concertgoers to continuously rate their felt "emotional force" at a concert premiere.

A dominant portion of the studies using a self-report approach rely on retrospective ratings of emotions, in which a rating/ratings are provided after a stimulus has been heard. However, music unfolds in time, and emotional experiences also change as a function of time. To capture the moment-by-moment fluctuations in emotional experiences, continuous self-report measures have occasionally been used (for example, Grewe et al., 2007a; Luck et al., 2008; Schubert 1999, 2001, 2004; Sloboda \& Lehmann, 2001). The disadvantages of using continuous measurements are the extra effort it takes for the participants to concentrate on the temporal fluctuations in their emotional experiences, and the more complicated analysis techniques needed to deal with such data. Physiological and neural measures are-almost by definition-temporal in nature, and in these cases the temporal dynamics involved are usually better developed. However, direct comparisons between continuous self-reports and physiological measures have not been common (e.g., Grewe et al., 2007a; Krumhansl, 1997). In our opinion, nonverbal, behavioral measures are too infrequently used to 
measure music-induced emotions. If we exclude the forced-choice response formats such as facial pictures representing different basic emotions, only isolated studies have applied nonverbal indicators of emotions. Two studies (Bigand et al., 2005, and Vieillard et al., 2008) have collected similarity ratings for emotional music, and thereby gained important insights into the ways in which people organize emotional music examples. As such, this method has the same discovery value as diary studies, which allow one to uncover such patterns between music, emotions, and everyday life that may not be detectable using theory-driven observations (such as self-reports with closed-response formats). Although some studies have tried to analyze movements during music-induced emotions (Boone \& Cunningham, 2001; Camurri, Lagerlöf, \& Volpe, 2003), or let the participants choose appropriate colors to match emotions (Bresin, 2005), cross-modal issues of music-induced emotion are still largely unexplored.

In most studies, lyrics are avoided in order to eliminate specific meanings generated by the verbal content. For example, instrumental classical music has been the musical style most commonly used, while jazz and film music also do not usually have lyrics. Only a few studies have looked into the question of how lyrics affect emotional meaning in music (Gfeller \& Coffman, 1991; Stratton \& Zalanowski, 1994; Sousou, 1997). For example, the findings of Ali and Peynircioğlu (2006) suggested that the musical content (melody in this case) has more power to moderate emotions than lyrics, although lyrics do seem to enhance negative emotions more easily than positive emotions. This issue could and should be addressed further, as in the context of everyday music consumption the question of how emotions are generated by lyrics is of paramount importance.

\section{Recommendations for Future Research}

A number of problematic notions from past music and emotion studies were brought up by the review. Several of these were already identified by Juslin and Laukka in their meta-analysis of discrete emotion studies in 2003, and many of these challenges are also the reason for the verdict on the confusing and inconsistent state of affairs given by Juslin and Västfjäll in 2008. Here, however, we outline the major challenges based on a wider variety of music and emotion studies (251), and suggest concrete plans of action for improvement.

\section{THEORETICAL COMMITMENT}

Perhaps the most critical shortcoming in the field has been the reluctance to commit to the underlying theories of emotions. Many of the concepts utilized in music and emotion studies (e.g., fear, empathy, arousal) carry much stronger implications of the underlying processes than are acknowledged or advocated in empirical studies. The theoretical discussions are rare, and the rare exceptions (e.g., Juslin \& Västfjäll, 2008) have therefore a large impact on the community. In practical terms, the most significant source of confusion within music and emotion studies stems from the fact that conceptual frameworks for emotions in music are applied in an inconsistent manner. This may seem critical and overly pessimistic, as the most common emotion models-the discrete and the dimensional-cover about $70 \%$ of the studies. This ostensible consensus also reveals the curious reliance on a few, contentious models that have been seriously challenged within the emotion literature. Russell's (1980) circumplex model, the emotion model most often used in music and emotion studies, has been criticized over the years, and models that distinguish between negative and positive affect dimensions (Thayer, 1989; Watson et al., 1988) and thus account for mixed emotions (Larsen \& Diener, 1992; Schimmack \& Grob, 2000) have not only been proposed but critically examined for nearly two decades. The latter critique of Russell's (1980) model is particularly relevant to the domain of music, since several studies have now demonstrated that mixed feelings and perceptions in response to music are common (Hunter et al., 2008; Hunter, Schellenberg, \& Schimmack, 2010), yet impossible to capture by such a model.

Also, the selection principles for the stimuli have not always been consistent with the type of emotion model adopted, as there are studies where discrete emotion excerpts were rated using dimensional concepts (e.g., Khalfa, Peretz, Blondin, \& Manon, 2002; Kreutz et al., 2008). Some studies even suggest that the two models are based on entirely different processes (Dellacherie, Ehrle, \& Samson, 2008; Gosselin et al., 2005; Khalfa, Delbe et al., 2008), and thus these possible underlying differences should be considered before freely mixing the two models. Furthermore, the increasing popularity of the simultaneous use of discrete and dimensional models is indicative of a search for an appropriate emotion framework that would encompass both.

Music-specific models-though still relatively rarely used-are clearly going to become more common in the near future, as a number of influential studies with lists of music-specific emotion concepts have recently emerged (Juslin et al., 2008, Juslin \& Laukka, 2004; Zentner et al., 2008). As these studies are not yet fully compatible with each other, more research is needed to assess how factors such as musical genre, individual differences, and the 
various mechanisms through which music induces emotions (for these, see Juslin \& Västfjäll, 2008) contribute to the variations in music-specific emotion concepts.

We strongly recommend that future studies would more explicitly justify their choices with regard to the emotion models and concepts used-both in the selection of the stimuli and in the subsequent self-reports/ analyses-and include critical discussions on the applicability and theoretical background of their chosen emotion models. Finally, the focus on either felt or perceived emotions needs to be unambiguously qualified in future studies, and care should be taken in communicating this to the participants as well.

\section{EMOTION VALIDATION USING MULTIPLE APPROACHES}

The application of several research approaches in a single study is not yet that common in the field of music and emotions, despite the fact that the many separate components that make up emotions may only be satisfactorily studied by using a combination of different approaches (biological, self-report, observation, etc.). Currently, the most popular approach is to use selfreport methods. This is probably due to the fact that nearly all other approaches also use self-reports as a complementary method-in order to verify that the participants are actually experiencing the appropriate emotions-while the actual focus is on biological, clinical, music analytic, or individual and cultural aspects of emotions. It is important to stress that although selfreport measures are an indispensable means of obtaining information about the emotions, feelings, and moods experienced by people, they have certain weaknesses (e.g., demand characteristics and the need for accurate introspection) that render the results obtained using these methods inconclusive. On the other hand, the findings obtained using biological or music analytic methods (for example) cannot be corroborated without self-reports. A valid and reliable understanding of musicinduced emotions can only emerge when multiple approaches-such as self-reports, biological measures, and indirect measures of felt emotion (for a review, see Västfjäll, 2008) - are simultaneously used to investigate a given problem. However, we understand that this is a challenging task, made even more complicated by the extant variety of emotion models and terminologies, not to mention the two kinds of emotion loci.

\section{ACKNOWLEDGING THE SIGNIFICANCE OF PARTICIPANT BACKGROUNDS}

Most music and emotion studies have focused on "samples of convenience" (i.e., student populations from Western universities) and have drawn music from a fairly narrow selection of musical genres (i.e., classical, jazz, and film soundtracks). It is safe to assume that the emotional response to a given piece of music will vary according age, cultural background, and musical taste. At the most fundamental level, cross-cultural studies on music and emotion are sorely needed in order to estimate the degree to which findings in the field can be generalized across cultures. The rarity of cross-cultural studies (only five in this review) is to be expected, given that such endeavours are extremely difficult, and are becoming ever more so due to the effects of continuing globalization. Even within these five cross-cultural studies, only one study included a sample population that was not familiar with Western music (Fritz et al., 2009).

Perhaps it could be suggested that not all cross-cultural studies need to compare two separate cultures (that have no contact with each other), but useful tests of generalizability could also be conducted within the different cultural practices in the West (i.e., between different musical traditions). It may also be that different musical genres lead to different spectrums of emotions, as the functions of music often vary depending on the genre.

\section{ECOLOGICALLY VALID MUSIC}

Classical music is still the dominant musical genre used in music and emotion studies (nearly half of the studies covered here). This echoes what Juslin and Laukka (2003) identified as one of the central areas for improvement in the field. That is to say that there is a need to have, in their words, "a greater variety of musical materials" (p. 804). The widespread use of classical music has even led some researchers to conclude that liking of classical music would be a prerequisite for experiencing strong, music-induced emotions (Kreutz et al., 2008), which is clearly a problem related to the stimulus material used. As classical music is predominantly used in music and emotion studies as well as in mood induction studies (60-70\% of the stimuli, see Västfjäll, 2002), we strongly recommend that at least the overly popular repertoire within the genre should be avoided. Furthermore, researchers should try to move beyond the outdated view that classical music would be emotionally and aesthetically superior to other types of music.

The acknowledgement that music-induced emotions are personal and depend on individual factors should be acted upon, and also incorporated into studies either by asking the participants to bring their own music, or by providing the participants with a large selection of music to choose from. Music that is ecologically valid should somehow be relevant for the people participating in listening experiments-be it music that they are exposed to on a daily basis, or music that they choose 
to listen to themselves. Much could be learned by investigating the music that people actually use to regulate their own emotions and moods. This is of course not possible for all kinds of study designs (e.g., factorial manipulations of various musical features), but it is clearly something that could be easily improved, provided that a suitable selection of protocols and acoustic analyses are established.

Despite the above-mentioned recommendations for using ecological valid stimulus materials, we do advocate the systematic manipulation of musical features using factorial designs. Although this may seem to go against the requirement for using ecologically valid stimuli, studies using controlled stimuli are still needed in order to disambiguate musical features from each other in a causal fashion. Finally, in the name of transparency and the facilitation of the replication, simulation, and generation of follow-up studies, we strongly urge researchers to share their stimulus sets in secure online repositories.

\section{CONCLUDING REMARKS}

This review has identified several key issues that are currently holding back advances in the field of music and emotions. We have provided explicit recommendations, and suggested that future studies should especially aim for theoretical consistency, the use of multiple approaches simultaneously, the use of ecologically valid stimulus material, and the careful consideration of participant backgrounds. Other points we would like to raise-such as the need to venture outside the laboratory to study emotions in the contexts in which they naturally occur, and the need to use a broader array of methods (e.g., diary studies, experience sampling studies) - have already been suggested by Juslin and Laukka (2003), but are nevertheless still topical. We might also add that despite the current efforts to capture the temporal nature of music-induced emotions with continuous self-report and biological approaches, this paradigm needs to be enlarged upon and incorporated into the majority of future studies. The results obtained in this review do not suggest that enough has already been done in these directions. The research on music and emotion has the capacity of being an area in which progress can be made towards understanding one of the most fascinating aspects of human life which is the cause of so much else beyond music-the full spectrum of emotional experiences. The obstacles in the way are outlined by Juslin and Västfjäll (2008) and this current study. These will hopefully be noted by future researchers who, by systematically avoiding them, will be able to take more reliable and purposeful steps towards understanding the psychological and biological foundations of musical emotions.

\section{Author Note}

This work was funded by the European Union (BrainTuning FP6-2004-NEST-PATH-028570) and the Academy of Finland (Finnish Centre of Excellence in Interdisciplinary Music Research). We thank Alex Reed for the terminological and language-related improvements.

Correspondence concerning this article should be addressed to Tuomas Eerola, Finnish Centre of Excellence in Interdisciplinary Music Research, Seminaarinkatu 35, B. O. Box 15, FI-40014 University of Jyväskylä, Finland. E-mail: tuomas.eerola@jyu.fi

\section{References}

\section{${ }^{*}$ References marked with an asterisk indicate studies included in the review.}

$\rightarrow{ }^{*}$ Adachi, M., \& Trehub, S. E. (1998). Children's expression of emotion in song. Psychology of Music, 26, 133-153.

$\rightarrow{ }^{*}$ Adachi, M., \& Trehub, S. E. (2002). Decoding the expressive intentions in children's songs. Music Perception, 18, 213-224.

$\rightarrow$ Albersnagel, F. A. (1988). Velten and musical mood induction procedures: A comparison with accessibility in thought associations. Behaviour Research and Therapy, 26, 79-96.

$\rightarrow{ }^{*}$ Alfredson, B. B., Risberg, J., Hagberg, B., \& Gustafson, L. (2004). Right temporal lobe activation when listening to emotionally significant music. Applied Neuropsychology, 11(3), 161-166.

$\rightarrow{ }^{*}$ Al., S. O., \& Peynirciğolu, Z. F. (2006). Songs and emotions: Are lyrics and melodies equal partners? Psychology of Music, 34, 511-534.
*Al'tman, Y. A., Alyanchikova, Y. O., GuZikov, B. M., \& ZАкнАRоvл, L. E. (2000). Estimation of short musical fragments in normal subjects and patients with chronic depression. Human Physiology, 26, 553-557.

*Altenmüller, K., Schuermann, K., Lim, V. K., \& Parlittz, D. (2002). Hits to the left, flops to the right: Different emotions during listening to music are reflected in cortical lateralisation patterns. Neuropsychologia, 40, 2242-2256.

Asmus, E. (1985). The development of a multidimensional instrument for the measurement of affective responses to music. Psychology of Music, 13, 19-30.

${ }^{*}$ Balkwill, L.-L., \& Thомpson, W. F. (1999). A cross-cultural investigation of the perception of emotion in music: Psychophysical and cultural cues. Music Perception, 17, 43-64. *Balkwill, L.-L., Thompson, W. F., \& Matsunaga, R. (2004). Recognition of emotion in Japanese, Western, and Hindustani 
music by Japanese listeners. Japanese Psychological Research, 46, 337-349.

${ }^{*}$ Banich, M. T., Stolar, N., Heller, W., \& Goldman, R. B. (1992). A deficit in right-hemisphere performance after induction of a depressed mood. Neuropsychology, 5, 20-27.

$\rightarrow$ Banse, R., \& Sherer, K. R. (1996). Acoustic profiles in vocal emotion expression. Journal of Personality and Social Psychology, 70, 614-636.

$\rightarrow{ }^{\star}$ Baraldi, F., De Poli, G., \& RodÀ, A. (2006). Communicating expressive intentions with a single piano note. Journal of $\mathrm{New}$ Music Research, 35(3), 197-210.

$\rightarrow$ Barrett, L. F., \& Russell, J. A. (1999). Structure of current affect. Current Directions in Psychological Science, 8, 10-14.

$\rightarrow$ BARretT, L. F., \& W W AGER, T. (2006). The structure of emotion: Evidence from the neuroimaging of emotion. Current Directions in Psychological Science, 15, 79-85.

$\rightarrow{ }^{*}$ BArTel, L. R. (1992). The development of the cognitiveaffective response test-music. Psychomusicology, 11, 15-26.

$\rightarrow{ }^{\star}$ Baumgartner, T., Esslen, M., \& Jancke, L. (2006). From emotion perception to emotion experience: Emotions evoked by pictures and classical music. International Journal of Psychophysiology, 60, 34-43.

$\rightarrow{ }^{\star}$ Behrens, G., \& Green, S. (1993). The ability to identify emotional content of solo improvisations performed vocally and on three different instruments. Psychology of Music, 21, 20-33.

$\rightarrow{ }^{*}$ Bever, T. G. (1988). A cognitive theory of emotion and aesthetics in music. Psychomusicology, 7, 165-175.

$\rightarrow{ }^{*}$ Bigand, E., Vieillard, S., Madurell, F., Marozeau, J., \& DAcquet, A. (2005). Multidimensional scaling of emotional responses to music: The effect of musical expertise and of the duration of the excerpts. Cognition and Emotion, 19, 11131139.

$\rightarrow{ }^{\star}$ Blood, A. J., \& Zatorre, R. J. (2001). Intensely pleasurable responses to music correlate with activity in brain regions implicated in reward and emotion. Proceeding of National Academy of Sciences, 98, 11818-11823.

$\rightarrow{ }^{*}$ Blood, A. J., Zntorre, R. J., Bermudez, P., \& Evans, A. C. (1999). Emotional responses to pleasant and unpleasant music correlate with activity in paralimbic brain regions. Nature Neuroscience, 2, 382-287.

$\rightarrow{ }^{*}$ Boone, R., \& Cunningham, J. (2001). Children's expression of emotional meaning in music through expressive body movement. Journal of Nonverbal Behavior, 25, 21-41.

$\rightarrow{ }^{\star}$ Bounuys, A. L., Bloem, G. M., \& Groothuis, T. G. G. (1995). Induction of depressed and elated mood by music influences the perception of facial emotional expressions in healthy subjects. Journal of Affective Disorders, 33, 215-226.

BREsin, R. (2005). What is the color of that music performance. In Proceedings of the International Computer Music Conference (pp. 367-370). Barcelona, Spain: International Computer Music Association. $\rightarrow{ }^{*}$ Bresin, R., \& Friberg, A. (2000). Emotional coloring of computer-controlled music performances. Computer Music Journal, 24(4), 44-63.

$\rightarrow{ }^{*}$ Brittin, R. V., \& DUKE, R. A. (1997). Continuous versus summative evaluations of musical intensity: A comparison of two methods for measuring overall effect. Journal of Research in Music Education, 45(2), 245-258.

$\rightarrow{ }^{*}$ Brosgole, L., \& Weisman, J. (1995). Mood recognition across the ages. International Journal of Neuroscience, 82, 169-189.

$\rightarrow{ }^{*}$ Brown, S., Martinez, M. J., \& Parsons, L. M. (2004). Passive music listening spontaneously engages limbic and paralimbic systems. NeuroReport, 15, 2033-2037.

Burkhardt, F., Paeschke, A., Rolfes, M., Sendlmeier, W., \& Weiss, B. (2005). A database of German Emotional Speech. In Proceedings of the INTERSPEECH 2005(pp. 1517-1520). Lisbon, Portugal: ISCA.

$\rightarrow$ Camurri, A., LagerlöF, I., \& Volpe, G. (2003). Recognizing emotion from dance movement: Comparison of spectator recognition and automated techniques. International Journal of Human-Computer Studies, 59, 213-225.

Cannam, C., Landone, C., Sandler, M., \& Bello, J. (2006). The sonic visualiser: A visualisation platform for semantic descriptors from musical signals. In Proceedings of ISMIR 2006, 7th International Conference on Music Information Retrieval (pp. 324-327). Victoria, Canada: University of Victoria, Canada.

$\rightarrow{ }^{*}$ Chapados, C., \& Levitin, D. (2008). Cross-modal interactions in the experience of musical performances: Physiological correlates. Cognition, 108, 639-651.

$\rightarrow{ }^{\star}$ Chen, J., Yuan, J., Huang, H., Chen, C., \& Li, H. (2008). Music-induced mood modulates the strength of emotional negativity bias: An ERP study. Neuroscience Letters, 445, 135139.

$\rightarrow{ }^{*}$ Chen, L., Zhou, S., \& Bryant, J. (2007). Temporal changes in mood repair through music consumption: Effects of mood, mood salience, and individual differences. Media Psychology, 9, 695-713.

$\rightarrow$ Cl.ark, D. M., \& Teasdale, J. D. (1985). Constraints on the effect of mood on memory. Journal of Personality and Social Psychology, 48, 1595-1608.

$\rightarrow{ }^{*}$ Coffman, D. D., Gfeller, K., \& Eckert, M. (1995). Effect of textual setting, training, and gender on emotional response to verbal and musical information. Psychomusicology, 14, 117-136.

$\rightarrow{ }^{*}$ Collier, G. L. (2007). Beyond valence and activity in the emotional connotations of music. Psychology of Music, 35, 110-131.

$\rightarrow{ }^{*}$ Collier, W., \& Hubbard, T. (2001a). Judgments of happiness, brightness, speed, and tempo change of auditory stimuli varying in pitch and tempo. Psychomusicology, 17, 36-55.

$\rightarrow{ }^{*}$ Coll.ier, W., \& HubBard, T. (2001b). Musical scales and evaluations of happiness and awkwardness: Effects of pitch, direction, and scale mode. American Journal of Psychology, 114, 355-375. 
$\rightarrow{ }^{*}$ Соок, N. (2007). The sound symbolism of major and minor harmonies. Music Perception, 24, 315-319.

$\rightarrow{ }^{*} \operatorname{CostA}$, M., Bitti, P. E. R., \& Bonfiglioli, L. (2000). Psychological connotations of harmonic musical intervals. Psychology of Music, 28, 4-22.

$\rightarrow{ }^{\star}$ CostA, M., FIne, P. A., \& BITT1, P. E. R. (2004). Interval distributions, mode, and tonal strength of melodies as predictors of perceived emotion. Music Perception, 22, 1-14.

$\rightarrow$ Cowie, R., \& Cornelius, R. (2003). Describing the emotional states that are expressed in speech. Speech Communication, 40, 5-32.

$\rightarrow{ }^{*}$ Cunningham, J., \& Sterling, R. (1988). Developmental change in the understanding of affective meaning in music. Motivation and Emotion, 12, 399-413.

$\rightarrow{ }^{\star}$ DAHL, S., \& Friberg, A. (2007). Visual perception of expressiveness in musicians' body movements. Music Perception, 24, 433-454.

$\rightarrow{ }^{*}$ Dall.a Bella, S., Peretz, I., Rousseau, L., \& Gosselin, N. (2001). A developmental study of the affective value of tempo and mode in music. Cognition, 80, B1-10.

$\rightarrow{ }^{*}$ Dellacherie, D., Ehrle, N., \& Samson, S. (2008). Is the neutral condition relevant to study musical emotion in patients? Music Perception, 25, 285-294.

$\rightarrow{ }^{*}$ Dibben, N. (2004). The role of peripheral feedback in emotional experience with music. Music Perception, 22, 79-115.

$\rightarrow{ }^{*}$ Dibben, N. (2006). Subjectivity and the construction of emotion in the music of Björk. Music Analysis, 25, 171-197.

Douglas-Cowie, E, Campbel., N, Cowie, R \& Ronch, P. (2003). Emotional speech: Towards a new generation of databases. Speech Communication, 40, 70-75.

$\rightarrow$ Eerol. , T., \& Vuoskoski, J. K. (2011). A comparison of the discrete and dimensional models of emotion in music. Psychology of Music, 39, 18-49.

$\rightarrow{ }^{*}$ Efimova, I., \& Budyka, E. (2006). The use of emotional evaluations of short musical fragments for analyzing the functional states of students. Human Physiology, 32, 278-281.

$\rightarrow$ EIJCK, K. (2001). Social differentiation in musical taste patterns. Social Forces, 79, 1163-1118.

$\rightarrow$ Екмил, P. (1992). An argument for basic emotions. Cognition and Emotion, 6, 169-200.

$\rightarrow$ Elfienbein, H. A., \& Ambady, N. (2002). On the universality and cultural specificity of emotion recognition: A metaanalysis. Psychological Bulletin, 128, 203-235.

$\rightarrow{ }^{\star}$ Eluis, R., \& Simons, R. (2005). The impact of music on subjective and physiological indices of emotion while viewing films. Psychomusicology, 19, 15-40.

*Eschrich, S., Münte, T., \& Altenmüller, E. (2008). Unforgettable film music: The role of emotion in episodic long-term memory for music. BMC Neuroscience, 9(48), doi: 10.1186/1471-2202-9-48

*Erkkil.̈, J., Gold, C., Fachner, J., Ala-Ruona, E., Punkanen, M., \& Vanhala, M. (2008). The effect of improvisational music therapy on the treatment of depression:
Protocol for a randomised controlled trial. BMC Psychiatry, 8, 50, doi: 10.1186/1471-244X-8-50

$\rightarrow{ }^{*}$ Etzel, J. A., Johnsen, E. L., Dickerson, J., Tranel, D., \& Adol.phs, R. (2006). Cardiovascular and respiratory responses during musical mood induction. International Journal of Psychophysiology, 61, 57-69.

$\rightarrow{ }^{*}$ Evans, P., \& Schubert, E. (2008). Relationships between expressed and felt emotions in music. Musicae Scientiae, 12, 75-99.

$\rightarrow{ }^{*}$ FaITh, M., \& Thayer, J. F. (2001). A dynamical systems interpretation of a dimensional model of emotion. Scandinavian Journal of Psychology, 42, 121-133.

$\rightarrow$ Farnsworth, P. R. (1954). A study of the Hevner adjective list. Journal of Aesthetics and Art Criticism, 13, 97-103.

$\rightarrow{ }^{*}$ Flom, R., Gentile, D., \& PiCK, A. (2008). Infants' discrimination of happy and sad music. Infant Behavior and Development, 31, 716-728.

${ }^{*}$ Flores-Gutiérrez, E. O., Diaz, J.-L., Barrios, F. A., FavilaHumara, R., Guevara, M. A., Rio-Portilla, Y., \& CorsiCABrera, M. (2007). Metabolic and electric brain patterns during pleasant and unpleasant emotions induced by music masterpieces. International Journal of Psychophysiology, 65, 69-84.

${ }^{*}$ FredRICKSON, W. E. (1995). A comparison of perceived musical tension and aesthetic response. Psychology of Music, 23, 81-87.

${ }^{*}$ Frego, R. J. D. (1999). Effects of aural and visual conditions on response to perceived artistic tension in music and dance. Journal of Research in Music Education, 47, 31-43.

FrIJDA, N. H. (2007). What might an emotion be? Comments on the comments. Social Science Information, 46, 433-443.

*Fritz, T., Jentschke, S., Gosselin, N., Sammler, D., Peretz, I., TURner, R., ET AL. (2009). Universal recognition of three basic emotions in music. Current Biology, 19, 573-576.

${ }^{*}$ Gabrielsson, A. (2002). Emotion perceived and emotion felt: Same or different. Musicae Scientiae, 2001-2002, 123-147.

*Gabrielsson, A., \& Juslin, P. N. (1996). Emotional expression in music performance: Between the performer's intention and the listener's experience. Psychology of Music, 24, 68-91.

${ }^{*}$ GABRielsson, A., \& LindSTröm, E. (1995). Emotional expression in synthesizer and sentograph performance. Psychomusicology, 14, 94-116.

Gabrielsson, A., \& Lindström, E. (2001). The influence of musical structure on emotional expression. In P. N. Juslin \& J. A. Sloboda (Eds.), Music and emotion: Theory and research (pp. 235-239). Oxford, UK: Oxford University Press.

Gabrielsson, A., \& Lindström, E. (2010). The influence of musical structure on emotional expression. In P. N. Juslin \& J. A. Sloboda (Eds.), Handbook of music and emotion: Theory, research, application (pp. 367-400). New York: Oxford University Press.

*Gabrielsson, A., \& Lindström Wik, S. (2003). Strong experiences related to music: A descriptive system. Musicae Scientiae, 7, 157-217. 
${ }^{*}$ Gagnon, L., \& Peretz, I. (2000). Laterality effects in processing tonal and atonal melodies with affective and nonaffective task instructions. Brain and Cognition, 43, 206-10.

${ }^{*}$ Gagnon, L., \& Perftz, I. (2003). Mode and tempo relative contributions to "happy - sad" judgments in equitone melodies. Cognition and Emotion, 17, 25-40.

${ }^{\star}$ Gerardi, G., \& Gerken, L. (1995). The development of affective responses to modality and melodic contour. Music Perception, 12, 279-279.

${ }^{*}$ Geringer, J. M., Cassidy, J. W., \& Byo, J. L. (1996). Effects of music with video on responses of nonmusic majors: An exploratory study. Journal of Research in Music Education, 44, 240-251.

${ }^{*}$ Gfeller, K., Asmus, E. P., \& Eckert, M. (1991). An investigation of emotional response to music and text. Psychology of Music, 19, 128-141.

${ }^{*}$ Gfellek, K., \& Coffman, D. D. (1991). An investigation of emotional response of trained musicians to verbal and music information. Psychomusicology, 10, 31-48.

${ }^{*}$ GIlboa, A., Bodner, E., \& Amir, D. (2006). Emotional communicability in improvised music: The case of music therapists. Journal of Music Therapy, 43, 198-225.

*Giomo, C. J. (1993). An experimental study of children's sensitivity to mood in music. Psychology of Music, 21, 141-162.

${ }^{*}$ Gloeckner, N. (2006). Psychophysiological investigation of emotional states evoked by music. In M. Baroni, A. R. Addessi, R. Caterina, \& M. Costa (Eds.), Proceedings of the 9th International Conference on Music Perception and Cognition (pp. 95-106). Bologna, Italy: ICMPC-ESCOM.

${ }^{*}$ GomeZ, P., \& DANUSER, B. (2004). Affective and physiological responses to environmental noises and music. International Journal of Psychophysiology, 53, 91-103.

${ }^{*}$ Gomez, P., \& DANUSER, B. (2007). Relationships between musical structure and psychophysiological measures of emotion. Emotion, 7, 377-387.

${ }^{*}$ Gorn, G., Pham, M. T., \& Sin, L. Y. (2001). When arousal influences ad evaluation and valence does not (and vice versa). Journal of Consumer Psychology, 11, 43-55.

*Gosselin, N., Peretz, I., Johnsen, E., \& Adol.phs, R. (2007). Amygdala damage impairs emotion recognition from music. Neuropsychologia, 45, 236-244.

*Gosselin, N., Peretz, I., Noulhiane, M., Hasboun, D., Beckett, C., Baulac, M., \& SAmson, S. (2005). Impaired recognition of scary music following unilateral temporal lobe excision. Brain, 128, 628-640.

*Gosselin, N., Samson, S., Adolphs, R., Noulhiane, M., Roy, M., Hasboun, D., ET AL. (2006). Emotional responses to unpleasant music correlates with damage to the parahippocampal cortex. Brain, 129, 2585-2592.

${ }^{*}$ Goydke, K. N., Altenmüller, E., Mollek, J., \& Munte, T. F. (2004). Changes in emotional tone and instrumental timbre are reflected by the mismatch negativity. Cognitive Brain Research, 21, 351-359.

*Green, A., Barentsen, K., Stødildde-Jørgensen, H., W allentin, M., Roepstorff, A., \& Vuust, P. (2008). Music in minor activates limbic structures: A relationship with dissonance? Neuroreport, 19, 711-715.

${ }^{*}$ GREGoRY, A. H., \& VARNEY, N. (1996). Cross-cultural comparisons in the affective response to music. Psychology of Music, 24, 47-52.

*Grewe, O., Nagel, F., Kopiez, R., \& Altenmüller, E. (2007a). Emotions over time: Synchronicity and development of subjective, physiological, and facial affective reactions to music. Emotion, 7, 774-788.

*Grewe, O., Nagel, F., Kopiez, R., \& Altenmüller, E. (2007b). Listening to music as a re-creative process: Physiological, psychological, and psychoacoustical correlates of chills and strong emotions. Music Perception, 24, 297-314.

${ }^{*}$ Gupta, U., \& Gupta, B. (2005). Psychophysiological responsivity to indian instrumental music. Psychology of Music, 33, 363-372.

${ }^{*}$ Hargreaves, D. J., \& North, A. C. (1999). The functions of music in everyday life: Redefining the social in music psychology. Psychology of Music, 27, 71-83.

${ }^{*}$ Herz, R. S. (1998). An examination of objective and subjective measures of experience associated to odors, music and paintings. Empirical Studies of the Arts, 16, 137-152.

Hevner, K. (1936). Experimental studies of the elements of expression in music. American Journal of Psychology, 48, 248-268.

${ }^{*}$ Holbrook, M. B., \& Anand, P. (1992). The effects of situation, sequence, and features on perceptual and affective responses to product designs: The case of aesthetic consumption. Empirical Studies of the Arts, 10, 19-31.

${ }^{*}$ Hoshino, E. (1996). The feeling of musical mode and its emotional character in a melody. Psychology of Music, 24, 29-46.

*Hunter, P. G., Schellenberg, G. E., \& Sсhimmack, U. (2008). Mixed affective responses to music with conflicting cues. Cognition and Emotion, 22, 327-352.

Hunter, P. G., Schellenberg, E. G., \& Schimmack, U. (2010). Feelings and perceptions of happiness and sadness induced by music: Similarities, differences, and mixed emotions. Psychology of Aesthetics, Creativity, and the Arts, 4, 47-56.

${ }^{*}$ Huron, D. (2008). A comparison of average pitch height and interval size in major-and minor-key themes: Evidence consistent with affect-related pitch prosody. Empirical Musicology Review, 3, 59-63.

${ }^{*}$ Husain, G., Thompson, W. F., \& Schellenberg, E. G. (2002). Effects of musical tempo and mode on arousal, mood, and spatial abilities. Music Perception, 20, 151-171.

${ }^{*}$ Ilie, G., \& Thompson, W. F. (2006). A comparison of acoustic cues in music and speech for three dimensions of affect. Music Perception, 23, 319-329. 
*Iwaki, H. T., Hayashi, M., \& Hori, T. (1997). Changes in alpha band EEG activity in the frontal area after stimulation with music of different affective content. Perceptual and Motor Skills, 84, 515-526.

*Iwanaga, M., \& Tsukamoto, M. (1998). Preference for musical tempo involving systematic variations of presented tempi for known and unknown musical excerpts. Perceptual and Motor Skills, 86, 31-41.

IZARD, C. E. (2007). Basic emotions, natural kinds, emotion schemas, and a new paradigm. Perspectives on Psychological Science, 2, 260-280.

${ }^{\star}$ Juslin, P. N. (1997a). Can results from studies of perceived expression in musical performances be generalized across response formats? Psychomusicology, 16, 77-101.

*Jusu.rn, P. N. (1997b). Emotional communication in music performance: A functionalist perspective and some data. Music Perception, 14, 383-418.

*Juslin, P. N. (1997c). Perceived emotional expression in synthesized performances of a short melody: Capturing the listeners's judgement policy. Musicae Scientiae, 1, 225-256.

*Juslin, P. N. (2000). Cue utilization in communication of emotion in music performance: Relating performance to perception. Journal of Experimental Psychology: Human Perception and Performance, 26, 1797-1813.

*Juslin, P. N., Friberg, A., \& Bresin, R. (2001). Toward a computational model of expression in music performance: The GERM model. Musicae Scientiae, 6, 63-122.

*Juslin, P., \& LAuKKa, P. (2000). Improving emotional communication in music performance through cognitive feedback. Musicae Scientiae, 4, 151-184.

*Juslin, P. N., \& LaukKa, P. (2003). Communication of emotions in vocal expression and music performance: Different channels, same code? Psychological Bulletin, 129, 770-814.

*Juslin, P. N., \& LAukKa, P. (2004). Expression, perception, and induction of musical emotions: A review and a questionnaire study of everyday listening. Journal of New Music Research, 33, 217-238.

*Juslin, P. N., Liljeströ̀, S., Vāstfjäll, D., Barradas, G., \& SILVA, A. (2008). An experience sampling study of emotional reactions to music: Listener, music, and situation. Emotion, 8, 668-683.

*Juslin, P. N., \& Madison, G. (1999). The role of timing patterns in recognition of emotional expression from musical performance. Music Perception, 17, 197-221.

Juslin, P. N., \& SlobodA, J. A. (Eds.). (2001). Music and emotion: Theory and research. Oxford, UK: Oxford University Press.

Juslin, P. N., \& Sloboda, J. A. (Eds.). (2010). Handbook of music and emotion: Theory, research and applications. Oxford, UK: Oxford University Press.
*Juslin, P. N., \& VĀstFjÄLL, D. (2008). Emotional responses to music: The need to consider underlying mechanisms.

Behavioral and Brain Sciences, 31, 559-575.

${ }^{*}$ Juslin, P. N., \& Zintner, M. R. (2001). Current trends in the study of music and emotion: Overture. Musicae Scientiae, 6, 3-22.

${ }^{*}$ Kabuto, M., Kageyama, T., \& Nitta, H. (1993). EEG power spectrum changes due to listening to pleasant music and their relation to relaxation effects. Nippon Eiseigaku Zasshi, 48, 807-818.

${ }^{*}$ Kallinen, K. (2005). Emotional ratings of music excerpts in the Western art music repertoire and their self-organization in the Kohonen neural network. Psychology of Music, 33, 373-393.

${ }^{*}$ Kallinen, K., \& RAVAJA, N. (2004). Emotion-related effects of speech rate and rising vs. falling background music melody during audio news: The moderating influence of personality. Personality and Individual Differences, 37, 275-288.

${ }^{*}$ Kallinen, K., \& Ravaja, N. (2006). Emotion perceived and emotion felt: Same and different. Musicae Scientiae, 10, 191-213.

${ }^{*}$ Kamenetsky, S. B., Hill, D. S., \& Trehub, S. E. (1997). Effect of tempo and dynamics on the perception of emotion in music. Psychology of Music, 25, 149-160.

${ }^{*}$ Kaminska, Z., \& Woolf, J. (2000). Melodic line and emotion: Cooke's theory revisited. Psychology of Music, 28, 133-153.

${ }^{*}$ Kastner, M. P., \& Crowder, R. G. (1990). Perception of the major/minor distinction: Emotional connotations in young children. Music Perception, 8, 189-202.

${ }^{*}$ Khalfa, S., Delbe, C., Bigand, E., Reynaud, E., Chauvel, P., \& Liegeois-Chauvel, C. (2008). Positive and negative music recognition reveals a specialization of mesio-temporal structures in epileptic patients. Music Perception, 25, 295-302.

*Khalfa, S., Peretz, I., Blondin. J.-P., \& Manon, R. (2002). Event-related skin conductance responses to musical emotions in humans. Neuroscience Letters, 328, 145-149.

${ }^{*}$ Khalfa, S., Roy, M., Rainville, P., Dalla Bella, S., \& Peretz, I. (2008). Role of tempo entrainment in psychophysiological differentiation of happy and sad music? International Journal of Psychophysiology, 68, 17-26.

* Khalfa, S., Schon, D., Anton, J., \& Liekgeois-Chauvel, C. (2005). Brain regions involved in the recognition of happiness and sadness in music. Neuroreport, 16, 1981-1984.

${ }^{*}$ KIM, J., \& ANDRÉ, E. (2008). Emotion recognition based on physiological changes in music listening. IEEE Transactions on Pattern Analysis and Machine Intelligence, 30, 2067-2083.

${ }^{*}$ Kinsella, M. P., \& Jones, V. (1990). Judgement of mood in music following right hemisphere damage. Archives of Clinical Neuropsychology, 5, 359-371.

KıvY, P. (1990). Music alone: Philosophical reflections on the purely musical experience. Ithaca, NY: Cornell University Press. 
${ }^{*}$ Koelsch, S. (2005). Investigating emotion with music: Neuroscientific approaches. Annals of the New York Academy of Sciences, 1060, 412-418.

*Koelsch, S., Fritz, T., Cramon, D. Y., Müller, K., \& FriedericI, A. D. (2006). Investigating emotion with music: An fMRI study. Human Brain Mapping, 27, 239-250.

${ }^{*}$ Koelsch, S., Fritz, T., \& Schlaug, G. (2008). Amygdala activity can be modulated by unexpected chord functions during music listening. Neuroreport, 19, 1815-1819.

${ }^{\star}$ Koelsch, S., Kilches, S., Steinbeis, N., \& Schelinski, S. (2008). Effects of unexpected chords and of performer's expression on brain responses and electrodermal activity. PLoS ONE, 3(7), e2631.

${ }^{*}$ KoneĊNI, V. J. (2008). Does music induce emotion? A theoretical and methodological analysis. Psychology of Aesthetics, Creativity, and the Arts, 2, 115-129.

${ }^{*}$ Konečni, V. J., Brown, A., \& Wanic, R. A. (2008). Comparative effects of music and recalled life-events on emotional state. Psychology of Music, 36, 289-308.

${ }^{\star}$ KoneČnI, V. J., WANIC, R. A., \& Brown, A. (2007). Emotional and aesthetic antecedents and consequences of music-induced thrills. American Journal of Psychology, 120, 619-643.

${ }^{\star}$ KopIEZ, R. (2007). EMuJoy: Software for continuous measurement of perceived emotions in music. Behavior Research Methods, 39, 283-290.

${ }^{*}$ Korhonen, M. D., Cliausi, D. A., \& Jernigan, M. E. (2006). Modeling emotional content of music using system identification. IEEE Transactions on Systems, Man, and Cybernetics, 36, 588-599.

*Kreutz, G., Bongard, S., Rohrmann, S., Hodapp, V., \& GrEBE, D. (2004). Effects of choir singing or listening on secretory immunoglobulin a, cortisol, and emotional state. Journal of Behavioral Medicine, 27, 623-635.

${ }^{*}$ Kreutz, G., Bongard, S., \& Von Jussis, J. (2002). Cardiovascular responses to music listening: The effects of musical expertise and emotional expression. Musicae Scientiae, 6, 257-278.

*Kreutz, G., Ott, U., Teichmann, D., Osawa, P., \& Vaitl, D. (2008). Using music to induce emotions: Influences of musical preference and absorption. Psychology of Music, 36, 101-126.

${ }^{\star}$ KrumhanSL, C. L. (1997). An exploratory study of musical emotions and psychophysiology. Canadian Journal of Experimental Psychology, 51, 336-352.

${ }^{*}$ Krumhansl, C. L. (1998). Topic in music: An empirical study of memorability, openness and emotion in Mozart's string quintet in C major and Beethoven's string quartet in A minor. Music Perception, 16, 119-134.

Lang, P. J., Bradley, M. M., \& Cuthbert, B. N. (1999). International affective picture system IAPS: Technical manual and affective ratings. Gainesville, FL: The Center for Research in Psychophysiology, University of Florida.
Larsen, R., \& Diener, E. (1992). Promises and problems with the circumplex model of emotion. Review of personality and social psychology, 13, 25-59.

Lartillot, O., \& Toiviainen, P. (2007). MIR in Matlab (II), A toolbox for musical feature extraction from audio. In S. Dixon, D. Bainbridge, \& R. Typke (Eds.), Proceedings of the 8th International Conference on Music Information Retrieval (pp. 237-244). Vienna, Austria: Osterreichische Computer Gesellschaft.

${ }^{*}$ LAUKKA, P. (2007). Uses of music and psychological well-being among the elderly. Journal of Happiness Studies, 8, 215-241.

${ }^{*}$ LaUkKa, P., \& Gabrielsson, A. (2000). Emotional expression in drumming performance. Psychology of Music, 28, 181-189.

${ }^{*}$ LehmanN, A. C. (1997). Research note: Affective responses to everyday life events and music listening. Psychology of Music, 25, 84-90.

*Leman, M., Vermeulen, V., De Voogdt, L., Moelants, D., \& Lesaffre, M. (2005). Prediction of musical affect using a combination of acoustic structural cues. Journal of New Music Research, 34, 39-67.

LeRdahl, F. (2001). Tonal pitch space. New York: Oxford University Press.

Lesiuk, T. (2005). The effect of music listening on work performance the effect of music listening on work performance the effect of music listening on work performance. Psychology of Music, 33, 173-191.

${ }^{*}$ Lindström, E. (2003). The contribution of immanent and performed accents to emotional expression in short tone sequences. Journal of New Music Research, 32, 269-280.

${ }^{*}$ Lindström, E. (2006). Impact of melodic organization on perceived structure and emotional expression in music. Musicae Scientiae, 10, 85-117.

*Lindström, E., Juslin, P. N., Bresin, R., \& Williamon, A. (2003). "Expressivity comes from within your soul": A questionnaire study of music students' perspectives on expressivity. Research Studies in Music Education, 20, 23-47.

*Livingstone, S., Muhl.bergier, R., Brown, A., \& Loch, A. (2007). Controlling musical emotionality: An affective computational architecture for influencing musical emotions. Digital Creativity, 18, 43-53.

${ }^{*}$ London, J. (2001). Some theories of emotion in music and their implications for research in music psychology. Musicae Scientiae, 6, 23-36.

${ }^{*}$ Lowis, M. J. (2002). Music as a trigger for peak experiences among a college staff population. Creativity Research Journal, 14, 351-359.

${ }^{*}$ Lu, L., Liv, D., \& Zhang, H. (2006). Automatic mood detection and tracking of music audio signals. IEEE Transactions on Audio, Speech, and Language processing, 14, 5-18.

${ }^{*}$ Luck, G., Riikkil.̈, K., Laktillot, O., Erkkil.̈, J., Toiviainen, P., MÄKEl.Ä, A., ET AL. (2006). Exploring relationships between level of mental retardation and features of music therapy 
improvisations: A computational approach. Nordic Journal of Music Therapy, 15, 30-48.

${ }^{*}$ Luck, G., Ritkkilā, K., Lartillot, O., ErkKilā, J., Toiviainen, P., Mä́nelä, A., et AL. (2008). Modelling the relationships between emotional responses to, and musical content of, music therapy improvisations. Psychology of Music, $36,25-45$.

${ }^{*}$ Lundquist, L. G., Carlsson, F., \& Hilmersson, P., \& JusLin, P. N. (2009). Emotional responses to music: Experience, expression, and physiology. Psychology of Music, 37, 61-90.

MacDonald, R. A. R., Mitchell, L. A., Dillon, T., Serpell, M. G., Davies, J. B., \& Ashley, E. A. (2003). An empirical investigation of the anxiolytic and pain reducing effects of music. Psychology of Music, 31, 187-203.

${ }^{*}$ MacDorman, K., Ough, S., \& Ho, C. (2007). Automatic emotion prediction of song excerpts: Index construction, algorithm design, and empirical comparison. Journal of New Music Research, 36, 281-299.

${ }^{*}$ Madison, G. (2000). Properties of expressive variability patterns in music performances. Journal of New Music Research, 29, 335-356.

${ }^{*}$ Madsen, C. K. (1997a). Emotional response to music as measured by the two-dimensional CRDI. Journal of Music Therapy, 34, 187-199.

${ }^{*}$ Madsen, C. K. (1997b). Emotional response to music. Psychomusicology, 16, 59-67.

${ }^{*}$ Madsen, C. K. (1998). Emotion versus tension in Haydn's symphony No. 104 as measured by the two-dimensional continuous response digital interface. Journal of Research in Music Education, 46, 546-554.

${ }^{*}$ Madsen, C. K., \& Frederickson, W. E. (1993). The experience of musical tension: A replication of Nielsen's research using the continuous response digital interface. Journal of Music Therapy, 30, 46-63.

${ }^{*}$ MAKRIS, I. (2003). Judging the pleasantness of contour-rhythmpitch-timbre musical combinations. American Journal of Psychology, 116, 581-611.

* Mancini, M., Bresin, R., \& Pelachaud, C. (2007). A virtual head driven by music expressivity. IEEE Transactions on Audio Speech and Language Processing, 15, 1833-1845.

${ }^{*}$ Martin, M. A., \& Metha, A. (1997). Recall of early childhood memories through musical mood induction. Arts in Psychotherapy, 24, 447-454.

* Matsurra, M. (1998). Effects of background music on differential digital photoplethysmograms and mood states. Japanese Journal of Physiological Psychology and Psychophysiology, 16, 13-23.

Mauss, I., \& Robinson, M. (2009). Measures of emotion: A review. Cognition and Emotion, 23, 209-237.

${ }^{*}$ McAdams, S., Vines, B., Vielll.ard, S., Smith, B., \& REynolds, R. (2004). Influences of large-scale form on continuous ratings in response to a contemporary piece in a live concert setting. Music Perception, 22, 297-350.

${ }^{*}$ McEvilly, D. K. (1999). Chills and tempo. Music Perception, $16,457-462$.

${ }^{*}$ McFarl.and, R. A., \& Kennison, R. F. (1989a). Handedness affects emotional valence asymmetry. Perceptual and Motor Skills, 68, 435-441.

${ }^{*}$ McFarl.and, R. A., \& Kennison, R. F. (1989b). Asymmetry in the relationship between finger temperature changes and emotional state in males. Biofeedback and Self Regulation, 14, 281-290.

McNair, D. M., Lorr, M., \& Droppleman, L. F. (1981). Manual for the profile of mood states. San Diego, CA: Educational and Industrial Testing Service.

Meyer, L. B. (1956). Emotion and meaning in music. Chicago, IL: Chicago University Press.

${ }^{*}$ Meyer, R. K., Palmer, C., \& Mazo, M. (1998). Affective and coherence responses to Russian laments. Music Perception, 16, 135-150.

${ }^{*}$ Miller, M. M., \& Strongman, K. T. (2002). The emotional effects of music on religious experience: A study of the pentecostal-charismatic style of music and worship. Psychology of Music, 30, 8-27.

*Mitterschiffthaler, M. T., Fu, C. H. Y., Dalton, J. A., Andrew, C. M., \& Williams, S. C. R. (2007). A functional MRI study of happy and sad affective states induced by classical music. Human Brain Mapping, 28, 1150-1162.

* Morozov, V. (1996). Emotional expressiveness of the singing voice: The role of macrostructural and microstructural modifications of spectra. Logopedics Phonatrics Vocology, 21, 49-58.

${ }^{*}$ Morton B. J., \& Trehub, S. E. (2007). Children's judgements of emotion in song. Psychology of Music, 35, 629-639.

Mulder, J., Ter Bogt, T. F. M., Raajumakers, Q. A. W., Gabhainn, S. N., \& Sikkema, P. (2009). From death metal to $\mathrm{R} \& \mathrm{~B}$ ? Consistency of music preferences among Dutch adolescents and young adults. Psychology of Music, 38, 67-83.

*Nagel, F., Kopiez, R., Grewe, O., \& Altenmülller, E. (2008). Psychoacoustical correlates of musically induced chills. Musicae Scientiae, 12, 101-113.

${ }^{*}$ Napoles, J., \& Madsen, C. (2008). Measuring emotional responses to music within a classroom setting. International Journal of Music Education, 26, 63-71.

${ }^{*}$ Nater, U. M., Abbruzzese, E., Krebs, M., \& Ehlert, U. (2006). Sex differences in emotional and psychophysiological responses to musical stimuli. International Journal of Psychophysiology, 62, 300-308.

${ }^{*}$ Nawrot, E. S. (2003). The perception of emotional expression in music: Evidence from infants, children and adults. Psychology of Music, 31, 75-92.

${ }^{*}$ Nielzen, S., Olsson, O., \& Öhman, R. (1993). On perception of complex sound in schizophrenia and mania. Psychopathology, 26, 13-23. 
${ }^{*}$ North, A. C., \& Hargreaves, D. J. (1997). Liking, arousal potential, and the emotions expressed by music. Scandinavian Journal of Psychology, 38, 45-53.

North, A. C., Hargreaves, D. J., \& Hargreaves, J. J. (2004). The uses of music in everyday life. Music Perception, 22, 63-99.

Nussbaum, C. O. (2007). The musical representation: Meaning, ontology, and emotion. Boston, MA; MIT Press.

${ }^{*}$ Nykliček, I., Thayer, J. F., \& Van Doornen, L. J. P. (1997). Cardiorespiratory differentiation of musically-induced emotions. Journal of Psychophysiology, 11, 304-321.

${ }^{*}$ OCKELFORD, A. (2005). Relating musical structure and content to aesthetic response: A model and analysis of Beethoven's Piano Sonata Op. 110. Journal of the Royal Musical Association, 130, 74-118.

Ortony, A., \& Turner, T. J. (1990). What's basic about basic emotions? Psychological Review, 97, 315-331.

*Pallesen, K., Brattico, E., Bailey, C., Korvenoja, A., Koivisto, J., Gjedde, A., \& Carlson, S. (2005). Emotion processing of major, minor, and dissonant chords. Annals of the New York Academy of Sciences, 1060, 450-453.

${ }^{*}$ Panksepp, J., \& BekKedal, M. Y. V. (1997). The affective cerebral consequence of music: Happy vs. sad effects on the EEG and clinical implications. International Journal of Arts Medicine, 5, 18-27.

*PANKSEPP, J. (1992). A critical role for 'affective neuroscience' in resolving what is basic about basic emotions. Psychological Review, 99, 554-560.

*PANKSEPp, J. (1995). The emotional sources of "chills" induced by music. Music Perception, 13, 171-207.

Panksepp, J. (1998). Affective neuroscience: The foundations of human and animal emotions. Oxford, UK: Oxford University Press.

Pelletier, C. L. (2004). The effect of music on decreasing arousal due to stress: A meta-analysis. Journal of Music Therapy, 41, 192-214.

Peretz, I. (2010). Towards a neurobiology of musical emotions. In P. N. Juslin \& J. A. Sloboda (Eds.), Handbook of music and emotion: Theory, research, applications (pp. 99-126). Oxford, UK: Oxford University Press.

*Peretz, I., Blood, A. J., Penhune, V., \& Zatorre, R. (2001). Cortical deafness to dissonance. Brain, 124, 928-940.

*Peretz, I., \& GaGnon, L. (1999). Dissociation between recognition and emotional judgements for melodies. Neurocase, 5 , 21-30.

*Peretz, I., Gagnon, L., \& Bouchard, B. (1998). Music and emotion: Perceptual determinants, immediacy, and isolation after brain damage. Cognition, 68, 111-141.

*Pigniatello, M. F., \& Rasar, L. A. (1989). A psychophysiological comparison of the Velten and musical mood induction techniques. Journal of Music Therapy, 26, 140-154.

Posner, J., Russell, J. A., \& Peterson, B. S. (2005). The circumplex model of affect: An integrative approach to affective neuroscience, cognitive development, and psychopathology. Development and Psychopathology, 17, 715-734.

*Ravaja, N., \& Kallinen, K. (2004). Emotional effects of startling background music during reading news reports: The moderating influence of dispositional BIS and BAS sensitivities. Scandinavian Journal of Psychology, 45, 231-238.

${ }^{*}$ Rawlings, D., \& Leow, S. H. (2008). Investigating the role of psychoticism and sensation seeking in predicting emotional reactions to music. Psychology of Music, 36, 269-287.

${ }^{*}$ Resnicow, J. E., Salovey, P., \& Repp, B. H. (2004). Is recognition of emotion in music performance an aspect of emotional intelligence? Music Perception, 22, 145-158.

${ }^{*}$ Rickard, N. S. (2004). Intense emotional responses to music: A test of the physiological arousal hypothesis. Psychology of Music, 32, 371-388.

${ }^{*}$ Ritossa, D. A., \& Rickand, N. S. (2004). The relative utility of 'pleasantness' and 'liking' dimensions in predicting the emotions expressed by music. Psychology of Music, 32, 5-22.

${ }^{*}$ Robazza, C., Macaluso, C., \& D’Urso, V. (1994). Emotional reactions to music by gender, age, and expertise. Perceptual and Motor Skills, 79, 939-944.

${ }^{*}$ Roy, M., Mailhot, J.-P., Gosselin, N., Paquette, S., \& Peretz, I. (2008). Modulation of the startle reflex by pleasant and unpleasant music. International Journal of Psychophysiology, 71, 37-42.

*Roy, M., Peretz, I., \& Rainvil.ie, P. (2008). Emotional valence contributes to music-induced analgesia. Pain, 134, 140-147.

${ }^{*}$ Rozin, A., Rozin, P., \& Goldberg, E. (2004). The feeling of music past: How listeners remember musical affect. Music Perception, 22, 15-39.

Russell, J. A. (1980). A circumplex model of affect. Journal of Personality and Social Psychology, 39, 1161-1178.

Russell, J. A. (1983). Pancultural aspects of human conceptual organization of emotions. Journal of Personality and Social Psychology, 45, 1281-1288.

SAlomonsson, B. (1989). Music and affects: Psychoanalytic viewpoints. Scandinavian Psychoanalytic Review, 12, 126-144.

*S ammler, D., Grigutsch, M., Fritz, T., \& Koelsch, S. (2007). Music and emotion: Electrophysiological correlates of the processing of pleasant and unpleasant music.

Psychophysiology, 44, 293-304.

*Särkämō, T., Tervaniemi, M., Laitinen, S., Forsblom, A., Soinila, S., Mikkonen, M., et al. (2008). Music listening enhances cognitive recovery and mood after middle cerebral artery stroke. Brain, 131, 866-876.

*Schellenberg, E. G., Krysciak, A. M., \& Campbell, R. J. (2000). Perceiving emotion in melody: Interactive effects of pitch and rhythm. Music Perception, 18, 155-171.

*Schellenberg, E. G., Nakata, T., Hunter, P. G., \& Tamoto, S. (2007). Exposure to music and cognitive performance: tests of children and adults. Psychology of Music, 35, 5-19. 
*SchellenberG, E. G., Peretz, I., \& Vieillard, S. (2008). Liking for happy- and sad-sounding music: Effects of exposure. Cognition and Emotion, 22, 218-237.

${ }^{*}$ Schirer, K. R. (1995). Expression of emotion in voice and music. Journal of Voice, 9, 235-248.

${ }^{*}$ Scherer, K. R. (2004). Which emotions can be induced by music? What are the underlying mechanisms? And how can we measure them? Journal of New Music Research, 33, 239-251.

Scherer, K. R., Banse, R., \& Wallbott, H. G. (2001). Emotion inferences from vocal expression correlate across languages and cultures. Journal of Cross-Cultural Psychology, 32, 76-92.

Scherer, K. R., \& Zentner, M. R. (2001). Emotional effects of music: Production rules. In P. N. Juslin \& J. A. Sloboda (Eds.), Music and emotion: Theory and research (pp. 361-392). Oxford, UK: Oxford University Press.

${ }^{*}$ Scherer, K. R., Zentner, M. R., \& Schacht, A. (2002). Emotional states generated by music: An exploratory study of music experts. Musicae Scientiae, 6, 149-172.

Schimmack, U., \& Grob, A. (2000). Dimensional models of core affect: A quantitative comparison by means of structural equation modeling. European Journal of Personality, 14, 325-345.

*Schmidt, L. A., \& Trainor, L. J. (2001). Frontal brain electrical activity (EEG) distinguishes valence and intensity of musical emotions. Cognition and Emotion, 15, 487-500.

${ }^{*}$ Schubert, E. (1996). Enjoyment of negative emotions in music: An associative network explanation. Psychology of Music, 24, 18-28.

${ }^{*}$ Schubert, E. (1999). Measuring emotion continuously: Validity and reliability of the two-dimensional emotion-space. Australian Journal of Psychology, 51, 154-165.

${ }^{*}$ Schubert, E. (2001). Correlation analysis of continuous emotional response to music: Correcting for the effects of serial correlation. Musicae Scientiae, Special Issue, 213-236.

${ }^{*}$ Schubert, E. (2003). Update of Hevner's adjective checklist. Perceptual and Motor Skills, 96, 1117-1122.

${ }^{*}$ Schubert, E. (2004). Modeling perceived emotion with continuous musical features. Music Perception, 21, 561-585.

${ }^{*}$ Schubert, E. (2007). The influence of emotion, locus of emotion and familiarity upon preference in music. Psychology of Music, 35, 499-515.

*Schutz, M., Huron, D., Keeton, K., \& Loewer, G. (2008). The happy xylophone: acoustics affordances restrict an emotional palate. Empirical Musicology Review, 3, 126-135.

*SiegWART, H., \& Scherer, K. (1995). Acoustic concomitants of emotional expression in operatic singing: The case of Lucia in Ardi gli incensi. Journal of Voice, 9, 249-260.

${ }^{*}$ Silvia, P. J., \& Abele, A. E. (2002). Can positive affect induce self-focused attention? Methodological and measurement issues. Cognition and Emotion, 16, 845-853.

${ }^{*}$ Sloboda, J. A. (1991). Music structure and emotional response: Some empirical findings. Psychology of Music, 19, 110-120.
*S Loboda, J. A. (2001). The "sound of music" versus the "essence of music": Dilemmas for music-emotion researchers: Commentary. Musicae Scientiae, 6, 237-255.

${ }^{*}$ Sloboda, J. A., \& Lehmann, A. C. (2001). Tracking performance correlates of changes in perceived intensity of emotion during different interpretations of a Chopin piano prelude. Music Perception, 19, 87-120.

Sloboda, J. A., \& O'Neil.t, S. A. (2001). Emotions in everyday listening to music. In P. N. Juslin \& J. A. Sloboda (Eds.), Music and emotion: Theory and research (pp. 415-430). Oxford, UK: Oxford University Press.

Sousou, S. D. (1997). Effects of melody and lyrics on mood and memory. Perceptual and Motor Skills, 85, 31-40.

*Spackman, M., Fujiki, M., Brinton, B., Nelson, D., \& Alt.en, J. (2005). The ability of children with language impairment to recognize emotion conveyed by facial expression and music. Communication Disorders Quarterly, 26, 131-143.

*Spreckelmeyer, K., Kutas, M., Urbach, T., Altenmứller, E., \& Mǘnte, T. (2006). Combined perception of emotion in pictures and musical sounds. Brain Research, 1070, 160-170.

*Steinbeis, N., Koelsch, S., \& Sloboda, J. A. (2006). The role of harmonic expectancy violations in musical emotions: Evidence from subjective, physiological, and neural responses. Journal of Cognitive Neuroscience, 18, 1380-1393.

Stratton, V. N., \& Zalınowski, A. H. (1994). Affective impact of music vs. lyrics. Empirical Studies of the Arts, 12, 173-184.

*Suda, M., Morimoto, K., ОватA, A., Kolzumi, H., \& Maki, A. (2008). Emotional responses to music: Towards scientific perspectives on music therapy. Neuroreport, 19, 75-78.

*Sundberg, J., Iwarsson, J., \& Hagegård, H. (1994). A singer's expression of emotions in sung performance. STL-QPSR, 35, 217-229.

*Tan, S., Spackman, M., \& Bezdek, M. (2007). Viewers' interpretations of film characters' emotions: Effects of presenting film music before or after a character is shown. Music Perception, 25, 135-152.

*Terwogt, M. M., \& V An Grinsven, F. (1988). Recognition of emotions in music by children and adults. Perceptual and Motor Skills, 67, 697-698.

*Terwogt, M. M., \& Van Grinsven, F. (1991). Musical expression of moodstates. Psychology of Music, 19, 99-109.

*Thaut, M. H., \& Davis, W. B. (1993). The influence of subject-selected versus experimenter-chosen music on affect, anxiety, and relaxation. Journal of Music Therapy, 30, 210-223.

THAYER, R. E. (1989). The biopsychology of mood and arousal. New York: Oxford University Press.

*Thayer, J. F., \& Faith, M. L. (2001). A dynamic systems model of musically induced emotions. Physiological and selfreport evidence. Annals of the New York Academy of Sciences, 930, 452-456. 
*Thoma, M., Ryf, S., Ehlert, U., \& Nater, U. (2006). Regulation of emotions by listening to music in emotional situations. In M. Baroni, A. R. Addessi, R. Caterina, \& M. Costa (Eds.), Proceedings of the 9th International Conference on Music Perception and Cognition (pp. 1088-1093). Bologna, Italy: ICMPC-ESCOM

*Thompson, W. F., \& Robitall., B. (1992). Can composers express emotions through music? Empirical Studies of the Arts, 10, 79-89.

*Thompson, W., Russo, F., \& Quinto, L. (2008). Audio-visual integration of emotional cues in song. Cognition and Emotion, 22, 1457-1470.

Thompson, W. F., Schellenberg, E. G., \& Husain, G. (2001). Arousal, mood, and the Mozart effect. Psychological Science, 12, 248-251.

*Timmers, R., \& Ashiey, R. (2007). Emotional ornamentation in performances of a Handel sonata. Music Perception, 25, 117-134.

*Timmers, R., Marolt, M., Camurri, A., \& Vol.pe, G. (2006). Listeners' emotional engagement with performances of a Scriabin etude: An explorative case study. Psychology of Music, 34, 481-510.

Trehub, S. E., \& Nakata, T. (2002). Emotion and music in infancy. Musicae Scientiae, Special issue 2001-2002, 37-61.

Tugade, M. M., Fredrickson, B. L., \& Feldman-Barrett, L. (2004). Psychological resilience and positive emotional granularity: Examining the benefits of positive emotions on coping and health. Journal of Personality, 72, 1161-1190.

*Unwin, M. M., Kenny, D. T., \& DAvis, P. J. (2002). The effects of group singing on mood. Psychology of Music, 30, 175-185.

Vaitl, D., Vehrs, W., \& Sternagel, S. (1993). Prompts leitmotif - emotion: Play it again, Richard Wagner. In N. Birnbaumer \& A. Öhman (Eds.), The structure of emotion: Psychophysiological, cognitive, and clinical aspects (pp. 169-189). Seattle, WA: Hogrefe \& Huber.

*VANDERARK, S. D., \& Ely, D. (1993). Cortisol, biochemical, and galvanic skin responses to music stimuli of different preference values by college students in biology and music. Perceptual and Motor Skills, 77, 227-234.

${ }^{*}$ V ÄSTFJäLl., D. (2002). Emotion induction through music: A review of the musical mood induction procedure. Musicae Scientiae, Special Issue, 173-209.

*Vieillard, S., Peretz, I., Gosselin, N., Khalfa, S., Gagnon, L., \& Bouchard, B. (2008). Happy, sad, scary and peaceful musical excerpts for research on emotions. Cognition and Emotion, 22, 720-752.

*Vines, B., Krumhansl, C., Wanderley, M., Ioana, M., \& Levitin, D. (2005). Dimensions of emotion in expressive musical performance. Annals of New York Academy of Sciences, 1060, 462-466.
${ }^{*}$ VINK, A. (2001). Music and emotion: Living apart together: A relationship between music psychology and music therapy. Nordic Journal of Music Therapy, 10, 144-158.

Vuoskoski, J. K., \& Eerol.A, T. (2011). The role of mood and personality in the perception of emotions represented by music. Cortex, 47, 1099-1106.

${ }^{*}$ Waterman, M. (1996). Emotional responses to music: Implicit and explicit effects in listeners and performers. Psychology of Music, 24, 53-67.

Watson, D., Clark, L. A., \& Tellegen, A. (1988).

Development and validation of brief measures of positive and negative affect: The PANAS scales. Journal of Personality and Social Psychology, 54, 1063-1070.

*Watson, D., Wiese, D., Vaidya, J., \& Tellegen, A. (1999). The two general activation systems of affect: Structural findings, evolutionary considerations, and psychobiological evidence. Journal of Personality and Social Psychology, 76, 820-838.

WEDIN, L. (1972). A multidimensional study of perceptualemotional qualities in music. Scandinavian Journal of Psychology, 13, 241-257.

*Wells, A., \& HaKanen, E. (1991). The emotional use of popular music by adolescents. Journalism Quarterly, 68, 445-454.

${ }^{*}$ Witvliet, C. V. O., \& Vrana, S. R. (2007). Play it again Sam: Repeated exposure to emotionally evocative music polarises liking and smiling responses, and influences other affective reports, facial EMG, and heart rate. Cognition and Emotion, 21, 1-23.

${ }^{*}$ Woody, R. H. (2002). Emotion, imagery and metaphor in the acquisition of musical performance skill. Music Education Research, 4, 213-224.

${ }^{*}$ WU, T.-L., \& Jeng, S.-K. (2006). Automatic emotion classification of musical segments. In M. Baroni, A. R. Addessi, R. Caterina, \& M. Costa (Eds.), Proceedings of the 9 th International Conference on Music Perception and Cognition (pp. 385-393). Bologna, Italy: ICMPC-ESCOM.

*YANG, Y., Lin, Y., Su, Y., \& Chen, H. (2008). A regression approach to music emotion recognition. IEEE Transactions on Audio Speech and Language Processing, 16, 448-457.

*ZANON, P., \& Poli, G. (2003). Estimation of parameters in rule systems for expressive rendering of musical performance. Computer Music Journal, 27, 29-46.

Zajonc, R. B. (1980). Feeling and thinking: Preferences need no inferences. American Psychologist, 35, 151-175.

*Zentner, M., Grandiean, D., \& Scherer, K. R. (2008). Emotions evoked by the sound of music: Differentiation, classification, and measurement. Emotion, 8, 494-521. 


\section{Appendix}

TABLE A1. Prevalence of Self-Report Approach to Music and Emotions Across Emotion Models (Columns) and Emotion Loci (Rows).

\begin{tabular}{|c|c|c|c|c|}
\hline & Discrete & Dimensional & Miscellaneous & Music-specific \\
\hline Felt & $\begin{array}{l}\text { Banich et al. (1992); } \\
\text { Baumgartner et al. (2006); } \\
\text { Etzel et al. (2006); Hunter } \\
\text { et al. (2008); Khalfa, } \\
\text { Delbe, et al. (2008); } \\
\text { Konečni et al. (2008); } \\
\text { Kreutz et al. (2002, 2008); } \\
\text { Krumhansl (1997); } \\
\text { Krumhansl, Wanderley, } \\
\text { Ioana, \& Levitin (2005); } \\
\text { Mitterschiffthaler et al. } \\
\text { (2007); Nykliček et al. } \\
\text { (1997); Roy et al. (2008b); } \\
\text { Scherer et al. (2002); } \\
\text { Thayer \& Faith (2001); } \\
\text { Vines, }\end{array}$ & $\begin{array}{l}\text { Altenmüller et al. (2002); } \\
\text { Blood \& Zatorre (2001); } \\
\text { Blood et al. (1999); Collier } \\
\text { (2007); Dibben (2004); } \\
\text { Ellis \& Simons (2005); } \\
\text { Evans \& Schubert (2008); } \\
\text { Faith \& Thayer (2001); } \\
\text { Gomez \& Danuser (2004, } \\
\text { 2007); Grewe et al. } \\
\text { (2007a); Hunter et al. } \\
\text { (2008); Husain et al. } \\
\text { (2002); Kabuto et al. } \\
\text { (1993); Kallinen \& Ravaja } \\
\text { (2004, 2006); Khalfa, } \\
\text { Delbe, et al. (2008a); } \\
\text { Koelsch et al. (2006); } \\
\text { Koelsch, Fritz, \& Schlaug } \\
\text { (2008); Konečni et al. } \\
\text { (2008); Kreutz, Bongard, } \\
\text { Rohrmann, Hodapp, \& } \\
\text { Grebe (2004); Kreutz et al. } \\
\text { (2008); Krumhansl (1997); } \\
\text { Leman et al. (2005); } \\
\text { McFarland \& Kennison } \\
\text { (1989a, 1989b); } \\
\text { Mitterschiffthaler et al. } \\
\text { (2007); Nater et al. (2006); } \\
\text { Nykliček et al. (1997); } \\
\text { Ravaja \& Kallinen (2004); } \\
\text { Rickard (2004); Roy, } \\
\text { Peretz, et al. (2008); Roy, } \\
\text { Mailhot, et al. (2008); } \\
\text { Schellenberg et al. (2007); } \\
\text { Schubert (2007); Thayer \& } \\
\text { Faith (2001); Vines et al. } \\
\text { (2005); Webster \& Weir } \\
\text { (2005); Witvliet \& Vrana } \\
\text { (2007) }\end{array}$ & $\begin{array}{l}\text { Alfredson, Risberg, } \\
\text { Hagberg, \& Sustafson } \\
\text { (2004); Bigand et al. } \\
\text { (2005); Efimova \& Budkya } \\
\text { (2006); Gabrielsson \& } \\
\text { Lindström (2003); Gupta } \\
\text { \& Gupta (2005); Husain } \\
\text { et al. (2002); Konečni, } \\
\text { Brown, \& Wanic (2007); } \\
\text { Kreutz et al. (2008); } \\
\text { Leman et al. (2005); Miller } \\
\text { \& Strongman (2002); } \\
\text { Matsuura (1998); Martin } \\
\text { \& Metha (1997); } \\
\text { McAdams et al. (2004); } \\
\text { Nagel, Kopiez, Grewe, \& } \\
\text { Altenmüller (2008); } \\
\text { Napoles \& Madsen (2008); } \\
\text { Panksepp (1995); Rozin, } \\
\text { Rozin, \& Goldberg (2004); } \\
\text { Schubert (2007); Sloboda } \\
\text { (1991); Thaut \& Davis } \\
\text { (1993); Timmers, Marolt, } \\
\text { Camurri, \& Volpe (2006) }\end{array}$ & $\begin{array}{l}\text { Bartel (1992); Coffman } \\
\text { et al. (1995); Collier } \\
\text { (2007); Dibben (2004); } \\
\text { Gfeller et al. (1991); } \\
\text { Gfeller \& Coffman (1991); } \\
\text { Giomo (1993); Juslin \& } \\
\text { Laukka (2004); Juslin et al. } \\
\text { (2008); Kaminska \& } \\
\text { Woolf (2000); Kinsella \& } \\
\text { Jones (1990); Lindström } \\
\text { et al. (2003); Scherer et al. } \\
\text { (2002); Schubert (2003); } \\
\text { Wells \& Hakanen (1991); } \\
\text { Zentner et al. (2008) }\end{array}$ \\
\hline Perce & $\begin{array}{l}\text { Adachi \& Trehub (2002); } \\
\text { Ali \& Peynircioglu (2006); } \\
\text { Balkwill \& Thompson } \\
\text { (1999); Balkwill, } \\
\text { Thompson, \& Matsunaga } \\
\text { (2004); Behrens \& Green } \\
\text { (1993); Boone \& } \\
\text { Cunningham (2001); } \\
\text { Bouhuys, Bloem, \& } \\
\text { Groothuis (1995); } \\
\text { Brosgole \& Weisman } \\
\text { (1995); Bresin \& Friberg } \\
\text { (2000); Chen, Yuan, } \\
\text { Huang, Chen, \& Li (2008); } \\
\text { Collier \& Hubbard (2001a, } \\
\text { 2001b); Cunningham \& } \\
\text { Sterling (1998); Dahl \& } \\
\text { Friberg (2007); Dalla Bella }\end{array}$ & $\begin{array}{l}\text { Costa, Fine, \& Bitti (2004); } \\
\text { Dibben (2004); Eschrich, } \\
\text { Münte, \& Altenmüller } \\
\text { (2008); Evans \& Schubert } \\
\text { (2008); Gagnon \& Peretz } \\
\text { (2000, 2003); Geringer } \\
\text { et al. (1996); Gorn, Pham, } \\
\text { \& Sin (2001); Gosselin } \\
\text { et al. (2005, 2006, 2007); } \\
\text { Holbrook \& Anand } \\
\text { (1992); Ilie \& Thompson } \\
\text { (2006); Iwanaga \& } \\
\text { Tsukamoto (1998); } \\
\text { Kallinen \& Ravaja (2006); } \\
\text { Khalfa, Delbe, et al. } \\
\text { (2008); Khalfa et al. } \\
\text { (2002); Khalfa, Roy, et al. } \\
\text { (2008); Khalfa, Schon, }\end{array}$ & $\begin{array}{l}\text { Baraldi, De Poli, \& Rodà } \\
\text { (2006); Brittin \& Duke } \\
\text { (1997); Costa, Bitti, \& } \\
\text { Bonfiglioni (2000); } \\
\text { Fredrickson (1995); Frego } \\
\text { (1999); Geringer et al. } \\
\text { (1996); Juslin (1997c); } \\
\text { Kamenetsky et al. (1997); } \\
\text { Krumhansl (1998); Leman } \\
\text { et al. (2005); Lindström } \\
\text { (2006); Madison (2000); } \\
\text { Madsen \& Frederickson } \\
\text { (1993); North \& } \\
\text { Hargreaves (1997); } \\
\text { Rawlings \& Leow (2008); } \\
\text { Ritossa \& Rickard (2004); } \\
\text { Schubert (2003, 2007) }\end{array}$ & $\begin{array}{l}\text { Bartel (1992); Gfeller et al. } \\
\text { (1991); Gfeller \& Coffman } \\
\text { (1991); Coffman et al. } \\
\text { (1995); Dibben (2004); } \\
\text { Giomo (1993); Juslin \& } \\
\text { Laukka (2004); Kaminska } \\
\text { \& Woolf (2000); Schubert } \\
\text { (2003); Siegwart \& Scherer } \\
\text { (1995); Zentner et al. } \\
\text { (2008) }\end{array}$ \\
\hline
\end{tabular}




\begin{tabular}{|c|c|c|c|c|}
\hline & Discrete & Dimensional & Miscellaneous & Music-specific \\
\hline & $\begin{array}{l}\text { et al. (2001); Fritz et al. } \\
\text { (1999); Gabrielsson \& } \\
\text { Juslin (1996); Gabrielsson } \\
\text { \& Lindström (1995); } \\
\text { Gerardi \& Gerken (1995); } \\
\text { Gilboa, Bodner, \& Amir } \\
\text { (2006); Gloeckner (2006); } \\
\text { Gosselin et al. (2005, 2006, } \\
\text { 2007); Gregory \& Varney } \\
\text { (1996); Green et al. (2008); } \\
\text { Juslin (1997a, 1997b, } \\
\text { 1997c, 2000); Juslin \& } \\
\text { Madison (1999); Kallinen } \\
\text { (2005); Kastner \& } \\
\text { Crowder (1990); Juslin } \\
\text { Meyer, Palmer, \& Mazo } \\
\text { (1998); Khalfa et al. } \\
\text { (2002); Khalfa, Delbe, } \\
\text { et al. (2008); Khalfa, Roy, } \\
\text { et al. (2008); Konečni et al. } \\
\text { (2008); Lindström et al. } \\
\text { (2006); Lu, Liu, \& Zhang } \\
\text { (2006); Madison (2000); } \\
\text { Mancini, Bresin, \& } \\
\text { Pelachaud (2007); } \\
\text { Morozov (1996); Nawrot } \\
\text { (2003); Morton \& Trehub } \\
\text { (2007); North \& } \\
\text { Hargreaves (1997); } \\
\text { Resnicow et al. (2004); } \\
\text { Robazza et al. (1994); Roy, } \\
\text { Mailhot, et al. (2008); } \\
\text { Särkämö et al. (2008); } \\
\text { Schellenberg, Krysciak, \& } \\
\text { Campbell (2000); } \\
\text { Schellenberg et al. (2008); } \\
\text { Spackman, Fujiki, } \\
\text { Brinton, Nelson, \& Allen } \\
\text { (2005); Spreckelmeyer, } \\
\text { Kutas, Urbach, } \\
\text { Altenmüller, \& Münte } \\
\text { (2006); Tan et al. (2007); } \\
\text { Terwogt \& Van Grinsven } \\
\text { (1988, 1991); Timmers \& } \\
\text { Ashley (2007); Vieillard } \\
\text { et al. (2008) }\end{array}$ & $\begin{array}{l}\text { Anton, \& Liègeois- } \\
\text { Chauvel (2005); Koelsch } \\
\text { et al. (2008a); Kopiez } \\
\text { (2007); Konečni et al. } \\
\text { (2008); Korhonen et al. } \\
\text { (2006); Leman et al. } \\
\text { (2005); Lindström (2003); } \\
\text { Lindström (2006); Luck } \\
\text { et al. (2008); MacDorman, } \\
\text { Ough, \& Ho (2007); } \\
\text { Madsen (1997a, 1998); } \\
\text { Pallesen et al. (2005); } \\
\text { Rawlings \& Leow (2008); } \\
\text { Ritossa \& Rickard (2004); } \\
\text { Roy, Mailhot, et al. } \\
\text { (2008b); Schubert (1999, } \\
\text { 2003, 2004, 2007); } \\
\text { Spreckelmeyer et al. } \\
\text { (2006); Terwogt \& } \\
\text { Van Grinsven (1991); } \\
\text { Thoma, Ryf, Ehlert, \& } \\
\text { Nater (2006); Thompson, } \\
\text { Russo, \& Quinto (2008); } \\
\text { Vieillard et al. (2008); Wu } \\
\text { \& Jeng (2006); Yang, Lin, } \\
\text { Su, \& Chen (2008) }\end{array}$ & & \\
\hline $\begin{array}{l}\text { Felt } \square \\
\quad \text { Perceived }\end{array}$ & $\begin{array}{l}\text { Khalfa, Delbe, et al. } \\
\text { (2008); Konečni et al. } \\
(2008)\end{array}$ & $\begin{array}{l}\text { Dibben (2004); Evans \& } \\
\text { Schubert (2008); Kallinen } \\
\text { \& Ravaja (2006); Khalfa, } \\
\text { Delbe, et al. (2008); } \\
\text { Konečni et al. (2008); } \\
\text { Leman et al. (2005); } \\
\text { Schubert (2007) }\end{array}$ & $\begin{array}{l}\text { Leman et al. (2005); } \\
\text { Panksepp (1995); } \\
\text { Schubert (2007) }\end{array}$ & $\begin{array}{l}\text { Dibben (2004); Juslin \& } \\
\text { Laukka (2004); Zentner } \\
\text { et al. (2008) }\end{array}$ \\
\hline
\end{tabular}


Table A1 (continued)

\begin{tabular}{|c|c|c|c|c|}
\hline & Discrete & Dimensional & Miscellaneous & Music-specific \\
\hline N/A & $\begin{array}{l}\text { Erkkilä et al. (2008); } \\
\text { Lundqvist, Carlsson, } \\
\text { Hilmersson \& Juslin } \\
\text { (2009); Pigniatello \& } \\
\text { Rasar (1989); Thompson } \\
\text { \& Robitaille (1992) }\end{array}$ & $\begin{array}{l}\text { Erkkilä et al. (2008); } \\
\text { Schmidt \& Trainor (2001); } \\
\text { Schubert (2001); Unwin, } \\
\text { Kenny, \& Davis (2002) }\end{array}$ & $\begin{array}{l}\text { Grewe et al. (2007b); Herz } \\
\text { (1998); Hoshino (1996); } \\
\text { Lehmann (1997); Lowis } \\
\text { (2002); Madsen (1997b); } \\
\text { Silvia \& Abele (2002); } \\
\text { Sloboda \& Lehmann } \\
\text { (2001); Steinbeis, Koelsch, } \\
\text { \& Sloboda (2006); } \\
\text { Waterman (1996); Woody } \\
\text { (2002) }\end{array}$ & $\begin{array}{l}\text { Kinsella \& Jones (1990); } \\
\text { Lindström et al. (2003); }\end{array}$ \\
\hline
\end{tabular}

TABLE A2. Prevalence of Music Analytic Approach to Music and Emotions Across Emotion Models (Columns) and Emotion Loci (Rows).

\begin{tabular}{|c|c|c|c|c|}
\hline & Discrete & Dimensional & Other & Music-specific \\
\hline Felt & Hunter et al. (2008) & $\begin{array}{l}\text { Grewe et al. (2007a); Hunter } \\
\text { et al. (2008); Husain et al. } \\
\text { (2002); Leman et al. (2005) }\end{array}$ & $\begin{array}{l}\text { Dibben (2006); Grewe et al. } \\
\text { (2007a); Husain et al. (2002); } \\
\text { Leman et al. (2005); McAdams } \\
\text { et al. (2004); Nagel et al. } \\
\text { (2008); Sloboda (1991); } \\
\text { Steinbeis et al. (2006); } \\
\text { Timmers et al. (2006) }\end{array}$ & - \\
\hline Perceived & $\begin{array}{l}\text { Adachi \& Trehub (1998); } \\
\text { Balkwill \& Thompson (1999); } \\
\text { Balkwill et al. (2004); Bresin \& } \\
\text { Friberg (2000); Dalla Bella } \\
\text { et al. (2001); Fritz et al. (2009); } \\
\text { Gabrielsson \& Juslin (1996); } \\
\text { Gabrielsson \& Lindström } \\
\text { (1995); Juslin (1997a, 1997b, } \\
\text { 2000); Juslin \& Laukka (2000); } \\
\text { Juslin \& Laukka (2003); } \\
\text { Laukka (2007); Laukka \& } \\
\text { Gabrielsson (2000); Lu et al. } \\
\text { (2006); Morozov et al. (1996); } \\
\text { Schellenberg et al. (2000); } \\
\text { Sundberg, Iwarsson, \& } \\
\text { Hagegård (1994); Thompson } \\
\text { \& Robitaille (1992); Timmers } \\
\text { \& Ashley (2007); Vieillard } \\
\text { et al. (2008); }\end{array}$ & $\begin{array}{l}\text { Costa et al. (2004); Gagnon \& } \\
\text { Peretz (2003); Ilie \& } \\
\text { Thompson (2006); Korhonen } \\
\text { et al.; (2006); Leman et al. } \\
\text { (2005); Livingstone, } \\
\text { Muhlberger, Brown, \& Loch; } \\
\text { (2007); Luck et al. (2006, } \\
\text { 2008); MacDorman et al. } \\
\text { (2007); Schubert (2004); } \\
\text { Vieillard et al.; (2008); Wu \& } \\
\text { Jeng (2006); Yang et al. (2008) }\end{array}$ & $\begin{array}{l}\text { Kamenetsky (1997); } \\
\text { Krumhansl (1998); Leman } \\
\text { et al. (2005) }\end{array}$ & $\begin{array}{l}\text { Kaminska \& } \\
\text { Woolf (2000); } \\
\text { Siegwart \& } \\
\text { Scherer } \\
(1995)\end{array}$ \\
\hline $\begin{array}{l}\text { Felt } \square \\
\quad \text { Perceived }\end{array}$ & - & Leman et al. (2005) & Leman et al. (2005) & \\
\hline N/A & $\begin{array}{l}\text { Goydke et al. (2004); Huron } \\
\text { et al. (2008); Schutz, Huron, } \\
\text { Keeton, \& Loewer (2008) }\end{array}$ & - & $\begin{array}{l}\text { Ockelford (2005); Sloboda } \\
\text { (2001); Waterman (1996); } \\
\text { Zanon \& Poli (2003); }\end{array}$ & - \\
\hline
\end{tabular}


TABLE A3. Prevalence of Biological Approach to Music and Emotions Across Emotion Models (Columns) and Emotion Loci (Rows).

\begin{tabular}{|c|c|c|c|c|}
\hline & Discrete & Dimensional & Other & Music-specific \\
\hline Felt & $\begin{array}{l}\text { Banich et al. (1992); } \\
\text { Baumgartner et al. (2006); } \\
\text { Etzel et al. (2006); Kreutz et al. } \\
\text { (2002); Krumhansl (1997); } \\
\text { Mitterschiffthaler et al. (2007); } \\
\text { Nykliček et al. (1997); Suda, } \\
\text { Morimoto, Obata, Koizumi, \& } \\
\text { Maki (2008) }\end{array}$ & $\begin{array}{l}\text { Altenmüller et al. (2002); } \\
\text { Blood \& Zatorre (2001); Blood } \\
\text { et al. (1999); Dibben (2004); } \\
\text { Ellis \& Simon (2005); Flores- } \\
\text { Gutierrez et al. (2007); Gomez } \\
\text { \& Danuser (2007); Grewe et al. } \\
\text { (2007a); Kabuto et al. (1993); } \\
\text { Kallinen \& Ravaja (2004); Kim } \\
\text { \& Andre (2008); Koelsch et al. } \\
\text { (2006); Kreutz et al. (2004); } \\
\text { Krumhansl (1997); McFarland } \\
\text { \& Kennison (1989a, 1989b); } \\
\text { Mitterschiffthaler et al. (2007); } \\
\text { Nater et al. (2006); Nykliček } \\
\text { et al. (1997); Ravaja \& Kallinen } \\
\text { (2004); Rickard (2004); Roy } \\
\text { et al. (2008a, 2008b); Sammler } \\
\text { et al. (2007); Schmidt \& } \\
\text { Trainor (2001); Witvliet \& } \\
\text { Vrana (2007); }\end{array}$ & $\begin{array}{l}\text { Alfredson et al. (2004); } \\
\text { Chapados \& Levitin (2008); } \\
\text { Grewe et al. (2007a, 2007b); } \\
\text { Gupta \& Gupta (2005); } \\
\text { Krumhansl (1997); Matsuura } \\
\text { (1998); VanderArk \& Ely } \\
\text { (1993); Steinbeis et al. (2006) }\end{array}$ & Dibben (2004) \\
\hline Perceived & $\begin{array}{l}\text { Gloeckner (2006); Gosselin } \\
\text { et al. (2005, 2006, 2007); } \\
\text { Khalfa et al. (2002); Khalfa, } \\
\text { Roy, et al. (2008); Peretz \& } \\
\text { Gagnon (1999); Peretz et al. } \\
\text { (1998, 2001); Spreckelmeyer } \\
\text { et al. (2006) }\end{array}$ & $\begin{array}{l}\text { Brown et al. (2004); Dibben } \\
\text { (2004); Gagnon \& Peretz } \\
\text { (2000); Gosselin et al. (2005, } \\
\text { 2006, 2007); Khalfa et al. } \\
\text { (2002, 2005); Khalfa, Roy, } \\
\text { et al. (2008) Pallesen et al. } \\
\text { (2005); Peretz et al. (2001); } \\
\text { Van Strien \& Boon (1997); } \\
\text { Spreckelmeyer et al. (2006) }\end{array}$ & $\begin{array}{l}\text { Brown et al. (2004); Peretz } \\
\text { et al. (2001) }\end{array}$ & Dibben (2004) \\
\hline $\begin{array}{l}\text { Felt } \square \\
\quad \text { Perceived }\end{array}$ & - & Dibben (2004) & - & Dibben (2004) \\
\hline N/A & $\begin{array}{l}\text { Erkkilä et al. (2008); Goydke } \\
\text { et al. (2004); Lundqvist et al. } \\
\text { (2009); Panksepp \& Bekkedal } \\
\text { (1997); Pigniatello \& Rasar } \\
\text { (1989) }\end{array}$ & Erkkilä et al. (2008) & $\begin{array}{l}\text { Herz (1998); Iwaki, Hayashi, } \\
\text { \& Hori (1997); Steinbeis et al. } \\
(2006)\end{array}$ & - \\
\hline
\end{tabular}

TABLE A4. Prevalence of Clinical Approach to Music and Emotions Across Emotion Models (Columns) and Emotion Loci (Rows).

\begin{tabular}{|c|c|c|c|c|}
\hline & Discrete & Dimensional & Other & Music-specific \\
\hline Felt & Khalfa, Delbe, et al. (2008) & Khalfa, Delbe, et al. (2008) & - & - \\
\hline Perceived & $\begin{array}{l}\text { Dellacherie et al. (2008); Gosselin et al. } \\
(2005,2006,2007) ; \text { Khalfa, Delbe, et al. } \\
\text { (2008); Peretz et al. (1998, 2001); } \\
\text { Särkämö et al. (2008); Spackman et al. } \\
\text { (2005) }\end{array}$ & $\begin{array}{l}\text { Al'tman et al. (2000); Gosselin et al. } \\
\text { (2005, 2006, 2007); Khalfa, Delbe, et al. } \\
\text { (2008); Luck et al. (2006); Peretz et al. } \\
\text { (2001) }\end{array}$ & $\begin{array}{l}\text { Nielzen et al. } \\
\text { (1993); } \\
\text { Peretz et al. } \\
(2001)\end{array}$ & - \\
\hline $\begin{array}{l}\text { Felt } \square \\
\quad \text { Perceived }\end{array}$ & Khalfa, Delbe, et al. (2008) & Khalfa, Delbe, et al. (2008) & - & - \\
\hline N/A & Erkkilä et al. (2008) & Erkkilä et al. (2008) & - & $\begin{array}{l}\text { Kinsella \& } \\
\text { Jones (1990) }\end{array}$ \\
\hline
\end{tabular}


TABLE A5. Prevalence of Developmental Approach to Music and Emotions Across Emotion Models (Columns) and Emotion Loci (Rows).

\begin{tabular}{|c|c|c|c|c|}
\hline & Discrete & Dimensional & Other & Music-specific \\
\hline Felt & - & - & - & - \\
\hline Perceived & $\begin{array}{l}\text { Adachi \& Trehub (1998, 2002); Boone \& Cunningham } \\
\text { (2001); Brosgole \& Weisman (1995); Cunningham \& Sterling } \\
\text { (1988); Dalla Bella et al. (2001); Flom, Gentile, \& Pick (2008); } \\
\text { Gerardi \& Gerken (1995); Kastner \& Crowder (1990); } \\
\text { Morton \& Trehub (2007); Nawrot (2003); Terwogt \& } \\
\text { Van Grinsven (1991) }\end{array}$ & $\begin{array}{l}\text { Terwogt \& } \\
\text { Van Grinsven } \\
\text { (1991) }\end{array}$ & $\begin{array}{l}\text { Boone \& } \\
\text { Cunningham } \\
(2001)\end{array}$ & Giomo (1993) \\
\hline $\begin{array}{l}\text { Felt } \square \\
\quad \text { Perceived }\end{array}$ & - & - & - & - \\
\hline N/A & - & - & - & - \\
\hline
\end{tabular}

TABLE A6. Prevalence of Individual and Cross-Cultural Approach to Music and Emotions Across Emotion Models (Columns) and Emotion Loci (Rows).

\begin{tabular}{|c|c|c|c|c|}
\hline & Discrete & Dimensional & Other & Music-specific \\
\hline Felt & $\begin{array}{l}\text { Kreutz, Bongard, \& Von Jussis } \\
\text { (2002); Kreutz, Ott, et al. (2008) }\end{array}$ & $\begin{array}{l}\text { Chen, Zhou, \& Bryant (2007); } \\
\text { Kabuto et al. (1993); Kallinen \& } \\
\text { Ravaja (2004); Kreutz, Ott, et al. } \\
\text { (2008); Nater et al. (2006) }\end{array}$ & $\begin{array}{l}\text { Bigand et al. (2005); } \\
\text { Efimova \& Budyka } \\
(2006) \text {; Kreutz, Ott, } \\
\text { et al. (2008) }\end{array}$ & - \\
\hline Perceived & $\begin{array}{l}\text { Balkwill \& Thompson (1999); } \\
\text { Balkwill et al. (2004); Fritz et al. } \\
\text { (2009); Gregory \& Varney (1996); } \\
\text { Meyer et al. (1998); }\end{array}$ & Rawlings \& Leow (2008) & $\begin{array}{l}\text { Rawlings \& Leow } \\
(2008)\end{array}$ & - \\
\hline $\begin{array}{l}\text { Felt } \square \\
\quad \text { Perceived }\end{array}$ & - & - & - & - \\
\hline
\end{tabular}

TABLE A7. List of Studies Applying Mainly Theoretical Approach to Music and Emotions.

Author

Bever (1988); Cook (2007); Dibben (2006; Gabrielsson (2002); Hargreaves \& North (1999); Holbrook \& Anand (1992); Juslin et al. (2001); Juslin \& Laukka (2003, 2004); Juslin \& Västfjäll (2008);

Juslin \& Zentner (2001); Koelsch (2005); Konečni (2008); Konečni et al. (2008); Livingstone et al. (2007); London (2001); Margulis (2008); McEvilly (1999); Ockelford (2005); Panksepp (1992, 1995); Salomonsson (1989); Scherer (1995, 2004); Schubert (1996); Sloboda (2001); Västfjäll (2002); Vink (2001) 